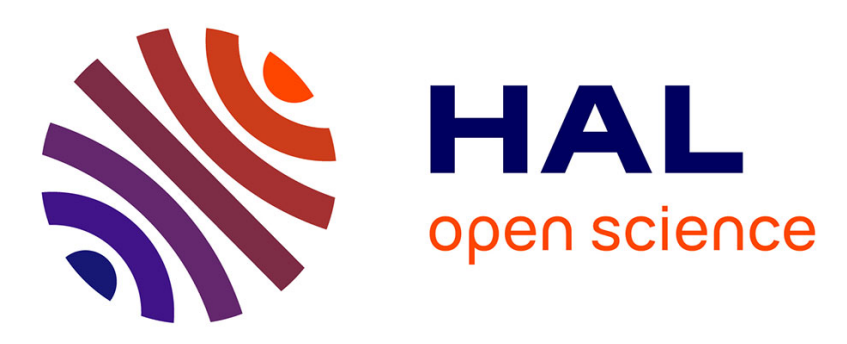

\title{
Cross-Linking of Poly(butylene terephthalate) by Reactive Extrusion Using Zn(II) Epoxy-Vitrimer Chemistry
}

Adrien Demongeot, Ramon Groote, Han Goossens, Theo Hoeks, Francois Tournilhac, Ludwik Leibler

\section{To cite this version:}

Adrien Demongeot, Ramon Groote, Han Goossens, Theo Hoeks, Francois Tournilhac, et al.. CrossLinking of Poly(butylene terephthalate) by Reactive Extrusion Using Zn(II) Epoxy-Vitrimer Chemistry. Macromolecules, 2017, 50 (16), pp.6117-6127. 10.1021/acs.macromol.7b01141 . hal-02396998

\section{HAL Id: hal-02396998 https://hal.science/hal-02396998}

Submitted on 6 Dec 2019

HAL is a multi-disciplinary open access archive for the deposit and dissemination of scientific research documents, whether they are published or not. The documents may come from teaching and research institutions in France or abroad, or from public or private research centers.
L'archive ouverte pluridisciplinaire HAL, est destinée au dépôt et à la diffusion de documents scientifiques de niveau recherche, publiés ou non, émanant des établissements d'enseignement et de recherche français ou étrangers, des laboratoires publics ou privés. 


\title{
Cross-linking of poly(butylene terephthalate) by reactive extrusion using Zn(II) epoxy-vitrimer chemistry
}

\author{
Adrien Demongeot, ${ }^{\dagger}$ Ramon Groote, ${ }^{\ddagger}$ Han Goossens, ${ }^{\ddagger}$ Theo Hoeks, ${ }^{\ddagger}$ François \\ Tournilhac, $^{\dagger^{*}}$ and Ludwik Leibler ${ }^{\dagger^{*}}$ \\ ${ }^{\dagger}$ Matière Molle et Chimie, UMR 7167 CNRS ESPCI Paris, PSL Research University, 10 rue Vauquelin 75005 Paris, \\ France. \\ ‡ SABIC T\&I, Plasticslaan 1, 4612 PX Bergen op Zoom, the Netherlands.
}

\begin{abstract}
Poly(butylene terephthalate) (PBT) vitrimers were prepared by reactive extrusion from industrial PBT thermoplastics using $\mathrm{Zn}$ (II)-catalyzed addition and transesterification chemistry. PBT thermoplastics are characterized by a high degree of crystallinity, high melting temperature and high crystallization rate, but right above their melting temperature their mechanical resistance disappear and they show a tendency to drip. We compared -OH and $-\mathrm{COOH}$ end-group additions on epoxies in the presence of two different catalysts, 2methyl imidazole (2-MI) and zinc acetyl acetonate $\left(\mathrm{Zn}(\mathrm{acac})_{2}\right)$. With 2-MI, chain extension reactions were efficiently catalyzed in a few minutes at $270{ }^{\circ} \mathrm{C}$ but no gelation was observed. With $\mathrm{Zn}(\mathrm{acac})_{2}$, $-\mathrm{COOH}$ addition and transesterification led to efficient cross-linking within a few minutes at $270{ }^{\circ} \mathrm{C}$. Such cross-linked material combines the crystalline properties of PBT and dimensional stability above the melting temperature. PBT materials cross-linked through epoxy-vitrimer chemistry are not soluble. However, compared with radiation cross-linked PBT, vitrimer PBT is processable and can be reshaped and recycled.
\end{abstract}




\section{Introduction}

Vitrimers, the third category of polymer materials, are networks made of chemically crosslinked polymers in which thermally stimulated exchange reactions permit network topology rearrangements while keeping constant the number of bonds and cross-links. In contrast to the two other categories of polymers, i.e., thermoplastics and thermosets, vitrimers combine insolubility and ability to flow when heated. The viscosity of vitrimers is controlled by the rate of the exchange reactions. The first vitrimers ${ }^{1}$ were based on epoxy-acid and epoxyanhydride chemistry and $\mathrm{Zn}(\mathrm{II})$-catalyzed transesterification exchanges. Subsequently, a number of monomers and exchange reactions have been used to synthesize vitrimers. ${ }^{2-13}$

The objective of this study is to show how the original $\mathrm{Zn}$ (II)-epoxy chemistry can be applied to synthesize semi-crystalline polyester vitrimers from commercial thermoplastic grades by a cross-linking method that can be used on an industrial scale. Our efforts focused on poly(butylene terephthalate) (PBT). The strategy is presented in Figure 1.

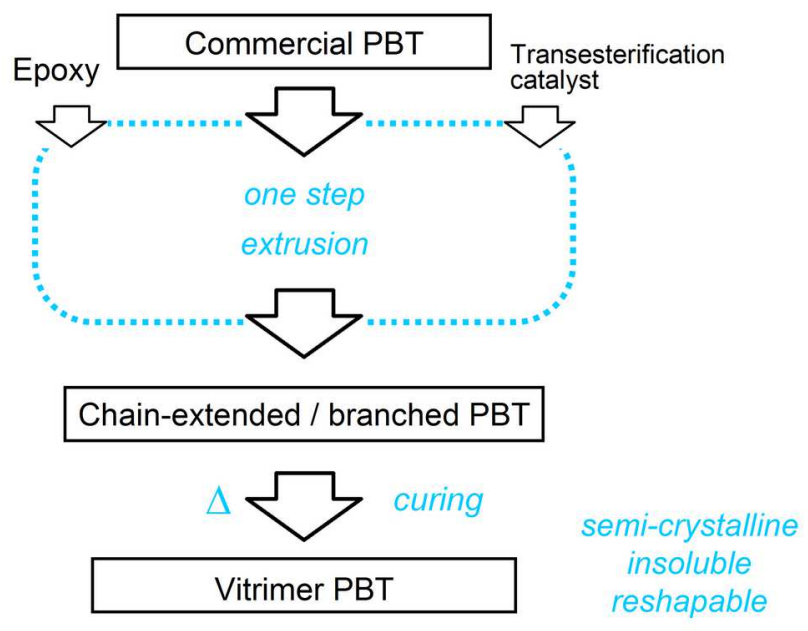

Figure 1 Flowchart of the chemical concept towards production of cross-linked PBT vitrimers with the help of epoxy vitrimer chemistry.

The formation of a chemically cross-linked polymer network is usually carried out either by reacting monomers with an average functionality greater than two or by cross-linking a preexisting thermoplastic polymer. In both cases, the process passes through a critical stage, the gelation point at which an infinite network is formed. Beyond the gelation threshold the system becomes an insoluble solid with a definite shape. During the synthesis of a vitrimer, a 
permanent covalent network is also formed; however, the network can change its topology thanks to exchange reactions. We use transesterification reactions to build the network. At the same time transesterification reactions impart to the network its dynamic properties at high temperatures. Interestingly, the same reaction, transesterification, is employed when PBT is produced from dimethyl terephthalate..

PBT is a semi-crystalline engineering plastic used in numerous industrial products, such as printed circuit board connectors, automobile parts, electrical appliance components and medical devices. In 2002 the production around the world exceeded $350 \mathrm{ktons}^{14}$ and raised up to 830 ktons in $2012 .{ }^{15}$ PBT has a high degree of crystallinity, typically $35-40 \%$ after injection molding which can be raised to $60 \%$ by annealing. ${ }^{14,16}$ Compared to polyamides, PBT has a low moisture absorption which makes it a good option for electrical insulation applications. ${ }^{17}$ Water absorption of PBT is less than $0.1 \%$ after $24 \mathrm{~h}^{14}$ and is about $0.5 \%$ in the saturated state. As a comparison, poly(amide-6) (PA-6) can absorb between 2 and $8 \%$ of water and its properties are strongly dependent on humidity. ${ }^{16-17}$

Commercial PBT, with $M_{n}$ ranging from 5,000 to $45,000 \mathrm{~g} / \mathrm{mol}$, is hardly entangled. ${ }^{18}$ The elastic modulus is approx. $2 \mathrm{GPa}$ at room temperature and in the $100 \mathrm{MPa}$ range at temperatures between $T_{g}$ of approx. $45^{\circ} \mathrm{C}$ and $T_{m}$ of approx. $225^{\circ} \mathrm{C} .{ }^{14,16,19}$ However, above the melting temperature, PBT exhibits low viscosity and PBT parts can flow under their own weight which significantly impacts the use of this polymer in high temperature applications. A radiation-induced cross-linking method is commonly used to improve the heat resistance of PBT. $^{20-22}$ Typical irradiation at a dose of $200 \mathrm{kGy}$ makes it possible to obtain high values of the gel fraction (> 99\%). ${ }^{23}$ The radiation-induced cross-linking process is irreversible. It needs to be performed on the parts in their final shape using electron or gamma radiation facilities.

In this paper, we describe a cross-linking method based on reactive mixing and extrusion. ${ }^{24-30}$ Usually, in reactive extrusion, precautions are taken to avoid gelation during the process. Indeed gelation can block the extruder. Here, thanks to the exchangeable nature of bonds the composition can be adjusted to assure the processability during a reactive mixing stage. When necessary, cross-linking can be completed after reactive mixing in an annealing step. 


\section{Experimental}

\subsection{Materials}

Two different PBT materials, specifically synthesized for this study, were obtained from SABIC. One referred as "High PBT" has molar masses of $M_{\mathrm{n}}=47 \mathrm{~kg} / \mathrm{mol}, M_{\mathrm{w}}=100 \mathrm{~kg} / \mathrm{mol}$ and end group concentrations of $[\mathrm{COOH}]=37 \mathrm{meq} / \mathrm{kg},[\mathrm{OH}]=23 \mathrm{meq} / \mathrm{kg}$. The other, referred as "Low PBT" has $M_{\mathrm{n}}=23 \mathrm{~kg} / \mathrm{mol}, M_{\mathrm{w}}=48 \mathrm{~kg} / \mathrm{mol}$, [COOH] $=17 \mathrm{meq} / \mathrm{kg}$ and $[\mathrm{OH}]$ $=120 \mathrm{meq} / \mathrm{kg}$. Before use, PBT pellets were dried for $16 \mathrm{~h}$ at $120^{\circ} \mathrm{C}$ under vacuum.

Diglycidyl ether of bisphenol A (DGEBA) with an [OH]/epoxy ratio lower than 0.03 , and an oligo-bisphenol A-co-epichlorohydrine solid epoxy resin, with an $[\mathrm{OH}] /$ epoxy of approx. 1.2, both produced by the Dow Chemical Company were used. 2-Methylimidazole (99\%), $\mathrm{NaCl}$ (99\%), ethyl acetate (99.5\%), 3-chloro-1,2-propanediol (98\%), pentaerythritol tetrakis(3,5-ditert-butyl-4-hydroxy hydro cinnamate) (Irganox 1010, 98\%) and bisphenol-A (99\%) were purchased from Sigma Aldrich. Zinc(II) acetyl acetonate (Zn(acac) $\left.)_{2}\right)(23.5$ to $26.0 \mathrm{wt} \% \mathrm{Zn}$ ) was purchased from Acros Organics. 1,1,2,2-tetrachloroethane (98\%), sodium hydroxide pellets (98\%), hydrochloric acid, 36\% w/w aqueous solution and 4-heptyl benzoic acid were purchased from Alpha Aesar. These products were used as received. Synthesis of bisphenol-A bis(2,3-dihydroxypropyl) ether is described in SI.

\subsection{Reactive mixing}

Modified PBT samples were prepared by reactive mixing. Typically, $10 \mathrm{~g}$ of well-dried PBT pellets were introduced via a hopper, together with the diepoxide (DGEBA, 0 to $0.4 \mathrm{~g}$ ), the esterification catalyst (2-MI, 0 to $5 \mathrm{mg}$ ) or trans-esterification catalyst ( $\mathrm{Zn}(\mathrm{acac})_{2}, 0$ to $36 \mathrm{mg}$ ) and an antioxidant (Irganox 1010, $10 \mathrm{mg}$ ) into a DSM Xplore 15-cc twin-screw minicompounder under a nitrogen flux. The rotor speed and the temperature were set respectively at $60 \mathrm{rpm}$ and $270{ }^{\circ} \mathrm{C}$. Mixing time was typically fixed at $10 \mathrm{~min}$. The axial force exercised on the barrel of the compounder, which can be used to follow qualitatively the change of viscosity, was recorded as a function of the residence time. In some experiments, aliquots of the reactive mixture were taken out from the compounder to perform ex-situ end-group analysis by FTIR spectroscopy. At high loading (3.6 wt\%) of diepoxide, part of the reactive mixture was purged out from the compounder after 5 min mixing to keep the axial force under the $8,000 \mathrm{~N}$ limitation of the equipment. 


\subsection{FTIR spectroscopy}

End-group analyses were carried out using the spectroscopic method developed by Ward and Kosky. ${ }^{31-33}$ Films were prepared by compression molding at $240{ }^{\circ} \mathrm{C}$ followed by rapid cooling in iced water resulting in samples with a thickness between 100 and $300 \mu \mathrm{m}$. The films were dried for $16 \mathrm{~h}$ at $90{ }^{\circ} \mathrm{C}$ before measurements. Samples were investigated by FTIR spectroscopy in transmission in the 4,000-400 $\mathrm{cm}^{-1}$ spectral range. First, the zero hydroxyl and carboxyl absorption levels were determined by using a deuterium exchanged sample (obtained by immersion in $\mathrm{D}_{2} \mathrm{O}$ at $90{ }^{\circ} \mathrm{C}$ for $24 \mathrm{~h}$ and dried $16 \mathrm{~h}$ at $90{ }^{\circ} \mathrm{C}$ ). Then, the spectra of the PBT materials were analyzed relative to the background level after normalization to take into account the actual thickness of each sample. The absorbance values corresponding to hydroxyl and carboxyl chain end-groups were measured at 3,550 and 3,270 $\mathrm{cm}^{-1}$, respectively (see SI, figure S1). Absolute calibration was done by recording the spectrum of the starting materials for which the end-group concentrations were known.

The reactive mixtures used for the model reactions were obtained by dissolving the reagents 4-heptyl benzoic acid, bisphenol-A bis(2,3-dihydroxypropyl ether), bisphenol-A diglycidyl ether, zinc(II) acetylacetonate and 2-methylimidazole in acetone. Stoichiometric ratios of 1:1 acyl-epoxy, 1:1 primary hydroxyl-epoxy and 0.05:1 catalyst-epoxy were used. The FTIR spectra were recorded at $4 \mathrm{~cm}^{-1}$ spectral resolution by using a Bruker TENSOR 37 spectrometer equipped with a DTGS detector and fitted with a Specac Golden Gate ATR heating cell. Samples were deposited on the ATR diamond heated at $200{ }^{\circ} \mathrm{C}$ resulting in a quick evaporation of acetone. The disappearance of the $910 \mathrm{~cm}^{-1}$ absorption peak $\left(v_{\mathrm{COC}}\right.$ epoxy) was monitored at a rate of one spectrum per minute (average of 32 scans) to determine the epoxy conversion (see SI, figure S2) In order to measure the initial height of the absorption peak and its evolution at short times $(<1$ minute) with sufficient accuracy, the experiment was repeated at a collection rate of 12 spectra per minute (average of 4 scans) using a liquid-nitrogen cooled MCT detector. The conversion was determined by the Lambert-Beer law from the normalized change of absorbance at $910 \mathrm{~cm}^{-1}$.

\subsection{Swelling tests}

To determine the gel fraction, $50 \mathrm{mg}$ of compound was immersed in $5 \mathrm{~mL}$ of 1,1,2,2tetrachloroethane for $16 \mathrm{~h}$ at $120{ }^{\circ} \mathrm{C}$. The gel was carefully separated from the solution, washed in chloroform during $24 \mathrm{~h}$, dried at $40^{\circ} \mathrm{C}$ for $16 \mathrm{~h}$ and weighted. 


\subsection{Thermal analysis}

Dynamic Mechanical Thermal Analysis (DMTA) experiments were carried out using a TA Instruments Q800 analyzer operating in film tension mode. Heating ramps were applied at 3 ${ }^{\circ} \mathrm{C} / \mathrm{min}$ from 10 to $260{ }^{\circ} \mathrm{C}$. Rectangular samples with a $5 \mathrm{~mm} \times 1.5 \mathrm{~mm}$ cross-section and about $10 \mathrm{~mm}$ length were tested at $1 \mathrm{~Hz}$ frequency and $15 \mu \mathrm{m}$ amplitude. Differential scanning calorimetric (DSC) measurements were performed using a DSC Q1000 from TA Instruments. The sample was heated to $235{ }^{\circ} \mathrm{C}$ at $10{ }^{\circ} \mathrm{C} / \mathrm{min}$, held at $235{ }^{\circ} \mathrm{C}$ for $2 \mathrm{~min}$, then cooled to $-90{ }^{\circ} \mathrm{C}$ at $10{ }^{\circ} \mathrm{C} / \mathrm{min}$, and finally heated to $235{ }^{\circ} \mathrm{C}$ at $10{ }^{\circ} \mathrm{C} / \mathrm{min}$. Melting temperatures, $T_{\mathrm{m}}$, and crystallization temperatures, $T_{\mathrm{c}}$, were determined as the temperatures of maximum endothermic (resp. exothermic) heat flow in DSC. The degree of crystallinity of the samples, $\chi_{\mathrm{c}}$, was determined by comparing the enthalpy of melting, $\Delta H_{m}$, measured by DSC at $10{ }^{\circ} \mathrm{C} / \mathrm{min}$ to the value reported in the literature for $100 \%$ crystallinity $\Delta H_{m}=140 \mathrm{~J} / \mathrm{g} .{ }^{14}$

\subsection{Rheometry}

Annealing experiments were monitored by rheometry using an Anton Paar MCR 501 analyzer operated with a $25 \mathrm{~mm}$ diameter parallel plate geometry. Samples of $1.5 \mathrm{~mm}$ thickness were investigated at $270{ }^{\circ} \mathrm{C}$ under nitrogen. The variations of $G$ ' and $G$ ', were recorded over time in the periodic oscillation regime $\left(\gamma=0.5 \%\right.$ and $\omega=1$ rad. $\left.\mathrm{s}^{-1}\right)$.

Frequency sweep experiments were performed using an ARES G2 rheometer. The measurements were carried out in the oscillatory shear mode using a $25 \mathrm{~mm}$ diameter parallel plate geometry. Frequency sweeps between 0.02 and $100 \mathrm{rad} / \mathrm{s}$ were carried out at $1 \%$ strain. Stress relaxation profiles were recorded using an ARES G2 rheometer in the $25 \mathrm{~mm}$ diameter parallel plate geometry on samples with thickness of $1.5 \mathrm{~mm}$ at a deformation of $1 \%$. Values of zero-shear viscosity, $\eta$ and relaxation time, $\tau$ were evaluated from the relaxation modulus, $G(t)$ through the equations: $\eta=\int G(t) d t ; \tau=\frac{1}{\eta} \int t G(t) d t$. 


\section{Results}

\subsection{Reactive mixing of PBT}

An overview of the characteristics of the compounds prepared and investigated in this work is presented in Table 1. The time variation of the $-\mathrm{COOH}$ and $-\mathrm{OH}$ end-group concentrations, as measured by FTIR spectroscopy, is plotted in Figures 2A and 2B. In Figure 2C, the axial force signal monitored by the system during mixing is also presented. An increase of this signal is expected in case of chain extension, branching and/or cross-linking reactions, whereas a decrease is expected in case of polymer chain scission reactions.

When extrusion is performed without DGEBA and catalyst on the high molecular weight PBT, compound 1 (black squares in Figure 2) the axial force is basically constant. In parallel the amount of $-\mathrm{COOH}$ groups during extrusion increases (Figure 2A). The measured increase of - $\mathrm{COOH}$ groups (from 37 to $40 \mathrm{meq} / \mathrm{kg}$ ) is not larger than $10 \%$. Experiments performed on high and low $M_{\mathrm{w}}$ PBT, with and without catalyst (see SI, figure S3) confirm that such an increase is systematically observed. The increase can be assigned to the thermal degradation of end groups through THF elimination. ${ }^{34-39}$

When DGEBA is added to PBT, compounds 2a-2d (green circles in Fig 2), we observe during mixing a decrease of the $-\mathrm{COOH}$ groups and an increase of the $-\mathrm{OH}$ groups concentrations. Evidently, the epoxy groups react with the carboxylic acid end-groups of PBT. However, the axial force signal does not change significantly and even in the presence of epoxy groups in excess, the consumption of $-\mathrm{COOH}$ groups is slow and not complete after 10 minutes of mixing.

For compounds 3a-3d (open blue triangles in Figure 2), the mixing of PBT with DGEBA is performed in the presence of 2-methylimidazole (2-MI), a known catalyst for the epoxy-acyl addition reaction.40-42 In this case, the decrease of the $-\mathrm{COOH}$ and increase of $-\mathrm{OH}$ concentrations are fast, consistent with epoxy-acyl additions, giving rise to hydroxy-esters. For instance, at a 1:1 stoichiometry the concentration of acid groups decreases to lower than $20 \%$ the initial value within 2 min of mixing (Figure 2A, left). During this period, a slight increase of the axial force is observed. When an excess of epoxy is used (middle and right panels of Figure 2), the consumption of the $-\mathrm{COOH}$ groups is completed within 2-3 minutes 
Table 1: Characteristics of prepared blends. *Determined by GPC using a PS standard with universal calibration. $\dagger$ Determined from DMTA traces at $\mathrm{T}=235^{\circ} \mathrm{C}$ and $\mathrm{f}=1 \mathrm{~Hz}$. $\ddagger$ Reactive mixing has been followed by curing. Not measurable by DMTA.

\begin{tabular}{|c|c|c|c|c|c|c|c|c|}
\hline \multirow[t]{2}{*}{ Compound } & \multicolumn{2}{|c|}{ Starting material } & \multirow{2}{*}{$\begin{array}{l}\text { DGEBA } \\
\text { Quantity (wt } \%)\end{array}$} & \multicolumn{2}{|l|}{ Catalyst } & \multirow{2}{*}{$\begin{array}{l}\text { Mixing } \\
\text { time } \\
\min \end{array}$} & \multirow{2}{*}{$\begin{array}{l}\begin{array}{c}\text { Insoluble } \\
\text { fraction }\end{array} \\
\%\end{array}$} & \multirow{2}{*}{$\frac{\mathrm{E}^{\prime \dagger}}{\mathrm{kPa}}$} \\
\hline & $M_{n} *(\mathrm{~kg} / \mathrm{mol})$ & $\frac{[\text { epoxy }]}{[\mathrm{OH}]+[\mathrm{COOH}]}$ & & Type & $\frac{[\text { catalyst }]}{[\mathrm{OH}]+[\mathrm{COOH}]}$ & & & \\
\hline 1 & 47 & 0 & 0 & none & 0 & 10 & 0 & \\
\hline 2.a & 47 & 1.0 & 1.1 & none & 0 & 10 & 0 & \\
\hline 2.d & 47 & 3.4 & 3.6 & none & 0 & 10 & 0 & \\
\hline 3.a & 47 & 1.0 & 1.1 & 2-MI & 0.1 & 10 & 0 & \\
\hline 3.d & 47 & 3.4 & 3.6 & 2-MI & 0.1 & 10 & 0 & \\
\hline 4.a & 47 & 1.0 & 1.1 & $\mathrm{Zn}(\mathrm{acac})_{2}$ & 0.1 & 10 & 4 & \\
\hline 4.b & 47 & 1.2 & 1.3 & $\mathrm{Zn}(\mathrm{acac})_{2}$ & 0.1 & 10 & 38 & $<100^{\circ}$ \\
\hline 4.c & 47 & 1.7 & 1.7 & $\mathrm{Zn}(\mathrm{acac})_{2}$ & 0.1 & 10 & 43 & 150 \\
\hline 4.d & 47 & 3.4 & 3.6 & $\mathrm{Zn}(\mathrm{acac})_{2}$ & 0.1 & 10 & 75 & 810 \\
\hline 5 & 47 & 1.7 & 1.7 & $\mathrm{Zn}(\mathrm{acac})_{2}$ & 0.1 & $2^{\ddagger}$ & 0 & \\
\hline 6 & 23 & 1.7 & 4.2 & $\mathrm{Zn}(\mathrm{acac})_{2}$ & 0.1 & $2^{\frac{1}{4}}$ & 0 & \\
\hline
\end{tabular}
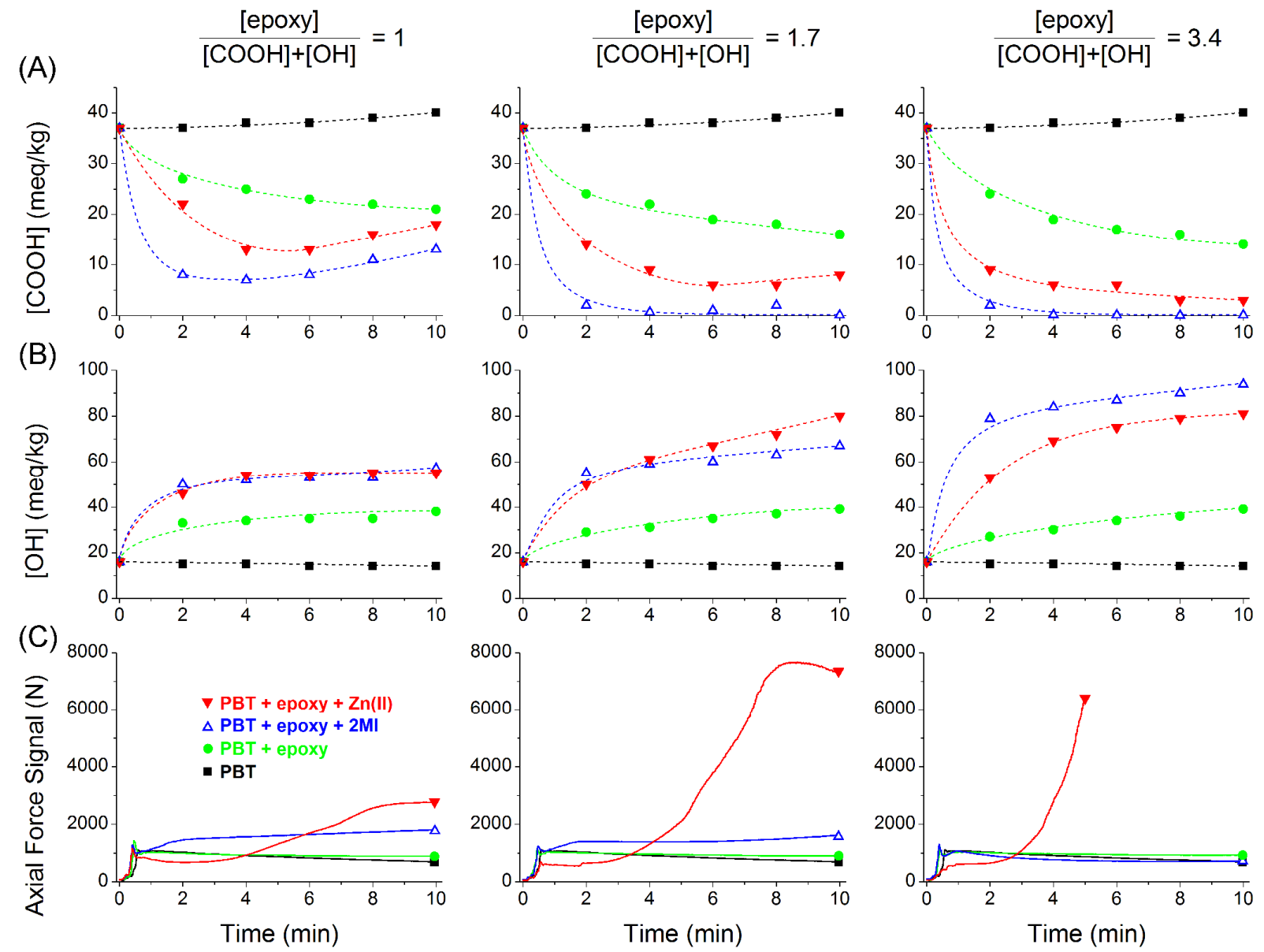

Figure 2 Chemical and mechanical monitoring during mixing for three epoxy end-groups ratios. (A) Variation of $-\mathrm{COOH}$ end-group content. (B) Variation of $-\mathrm{OH}$ group content. (C) Variation of the axial force as a function of reaction time at $270{ }^{\circ} \mathrm{C}$ and $60 \mathrm{rpm}$ under $\mathrm{N}_{2}$ flow. 
of mixing with no dramatic effect on the axial force. These observations indicate that 2-MI promotes PBT chain extension.

In contrast, when mixing with DGEBA is performed in the presence of the transesterification catalyst $\mathrm{Zn}(\mathrm{II})$ acetyl acetonate $\left(\mathrm{Zn}(\mathrm{acac})_{2}\right)$, compounds $\mathbf{4 a - 4 d}$ (filled red triangles in figure 2), the decay of $-\mathrm{COOH}$ groups is slower than with 2-MI, indicating that $\mathrm{Zn}$ (II) is a less efficient catalyst than 2-MI for the epoxy-acyl addition. However, the increase of -OH group concentration is fast and after five minutes of mixing, the axial force increases abruptly. All these observations suggest that in presence of $\mathrm{Zn}$ (II) cross-linking reactions, due to transesterification are efficiently catalyzed.

\subsection{Curing and gelation}

The change of flow properties revealed by a sharp increase of the axial force during mixing in the presence of the transesterification catalyst was analyzed quantitatively by rheometry. Two samples, compounds 5 and 6 respectively based on High-PBT $\left(M_{\mathrm{n}}=47 \mathrm{~kg} / \mathrm{mol}\right)$ and Low$\operatorname{PBT}\left(M_{\mathrm{n}}=23 \mathrm{~kg} / \mathrm{mol}\right)$, were first mixed $\left(2 \mathrm{~min}\right.$ at $\left.270{ }^{\circ} \mathrm{C}\right)$ with DGEBA and $\mathrm{Zn}(\mathrm{acac})_{2}$, both at the same molar concentration, in the extruder. Then, the compounds were annealed in-situ in a rheometer at $270{ }^{\circ} \mathrm{C}$. Shortly after extrusion, the measured viscosity was approx. 300 Pa.s for compound 5 and 10 Pa.s for compound 6. The time dependencies of the storage, $G$ ', and loss, $G^{\prime}$, moduli are presented in Figure 3A. In both cases, a rise of the moduli was observed within $10^{2}-10^{3}$ seconds. Moreover, the rheological data show that the $G$ ' and $G$ ', plots cross each other, which strongly suggests that gelation takes place in this time range. The crossover was observed earlier for compound 5 (after about $5 \mathrm{~min}$ ) than for compound $\mathbf{6}$ (after about $12 \mathrm{~min}$ ). However, compound 6 eventually reached a higher value of $G^{\prime}$ after complete reaction. Indeed, for PBT of lower molar mass (compound 6), complete curing with the same molar concentration of diepoxide, yields a higher density of cross-links.

The occurrence of gelation was checked by swelling tests performed in 1,1,2,2tetrachloroethane, a good solvent for non-cross-linked PBT. Before curing in the rheometer, both compounds $\mathbf{5}$ and $\mathbf{6}$ were soluble. After curing in the rheometer, the samples swelled but remained insoluble, confirming gelation. These experiments demonstrate that, despite important differences in molecular weight and end-group concentrations, the materials in both 
cases were eventually cross-linked beyond the gel point after full reaction. The same process proved to be efficient for the two used PBT materials.

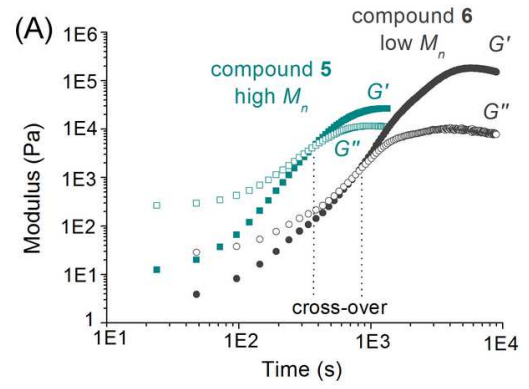

(B)

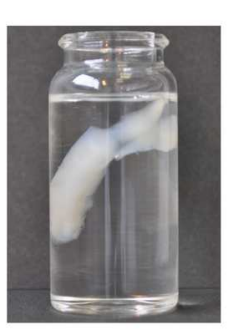

Figure 3 Gelation: (A) time dependence of the storage shear modulus $G^{\prime}$ (filled symbols) and loss modulus $G^{\prime}$ ' (open symbols) at $270{ }^{\circ} \mathrm{C}$ after a 2 min reactive mixing stage for PBT of two different molecular weights: compound 5 (squares) and 6 (circles). (B) Swelling of a PBT sample cross-linked beyond gelation (compound 4d, immersed in TCE at $120^{\circ} \mathrm{C}$ for $16 \mathrm{~h}$ and then cooled to room temperature).

After 10 min of mixing, the samples were not soluble (Figure 3B). Values of insoluble fractions are reported in Table 1. We observed that all samples extruded without catalyst (compound 1 and compounds 2a-2d) eventually dissolved. Swelling experiments for samples extruded with the esterification catalyst 2-MI (compounds 3a-3d) revealed no gel formation during the extrusion time used in this study $(10 \mathrm{~min})$. At longer extrusion times, small gel particles were observed for 1.7 and $3.6 \mathrm{wt} \%$ loadings of diepoxide as already reported in other studies. ${ }^{43-44}$ Eventually, samples mixed with at least one equivalent of DGEBA and the $\mathrm{Zn}$ (II) transesterification catalyst (compounds $\mathbf{4 a - 4 d ) ~ s y s t e m a t i c a l l y ~ s h o w e d ~ g e l a t i o n ; ~ a n ~ e x a m p l e ~ o f ~}$ unswollen and swollen specimen (compound 4c) is shown in ESI (figure S4). Moreover, when the $[$ epoxy $] /([\mathrm{OH}]+[\mathrm{COOH}])$ ratio was varied from 1.0 to 3.4 eq., the gel fraction increased from 4 to $75 \%$. (Table 1 ).

\subsection{Thermal analysis}

The results of DMTA and DSC experiments are reported in Figure 4 and in SI, Figure S4. Figure 4A shows the cooling curves of the pristine and modified PBT samples as recorded by DSC. In the 1, 4a-4d series the crystallization temperature $T_{\mathrm{c}}$ and degree of crystallinity $\chi_{\mathrm{c}}$ vary non-monotonically as a function of the amount of diepoxide. The pristine PBT shows a crystallization exotherm with a peak minimum at $186{ }^{\circ} \mathrm{C}$. For loadings of DGEBA lower than $1.7 \mathrm{wt} \%$ (compounds $\mathbf{4 a - 4 c}$ ), the crystallization temperature increases $\left(T_{\mathrm{c}}=200-202{ }^{\circ} \mathrm{C}\right.$ ), together with a slight increase of the degree of crystallinity for compound 4a (Figure S5C) meaning that in the cross-linked materials low loadings of diepoxide have a nucleation effect. This is also reflected in the DMTA data (Figure 4B) where higher values of $E$ ' between $T_{\mathrm{g}}$ 
and $T_{\mathrm{m}}$ are found suggesting a higher degree of crystallinity for compounds $\mathbf{4 b}$ and $\mathbf{4 c}$. At 3.6 wt\% loading (compound 4d), the melting and crystallization temperatures as well as the degree of crystallinity are lower than those of pristine PBT and, consequently, the observed $E$, value between $T_{\mathrm{g}}$ and $T_{\mathrm{m}}$ is also lower. Thus, modification of PBT has two opposite effects: on one hand, cross-linking reduces the ability to crystallize; on the other hand, modifiers have a nucleation effect. At low loadings of diepoxide, these two effects practically compensate each other and thus, compounds $\mathbf{4 a}, \mathbf{4 b}$ and $\mathbf{4 c}$ show similar values of $T_{\mathrm{c}}, T_{\mathrm{m}}$ and $\chi_{\mathrm{c}}$. At high loading (compound 4d) nucleation does not increase anymore but cross-links' density is clearly detrimental to crystallization. Consequently, compound $\mathbf{4 d}$ shows lower $T_{\mathrm{c}}, T_{\mathrm{m}}$, and $\chi_{\mathrm{c}}$ values.
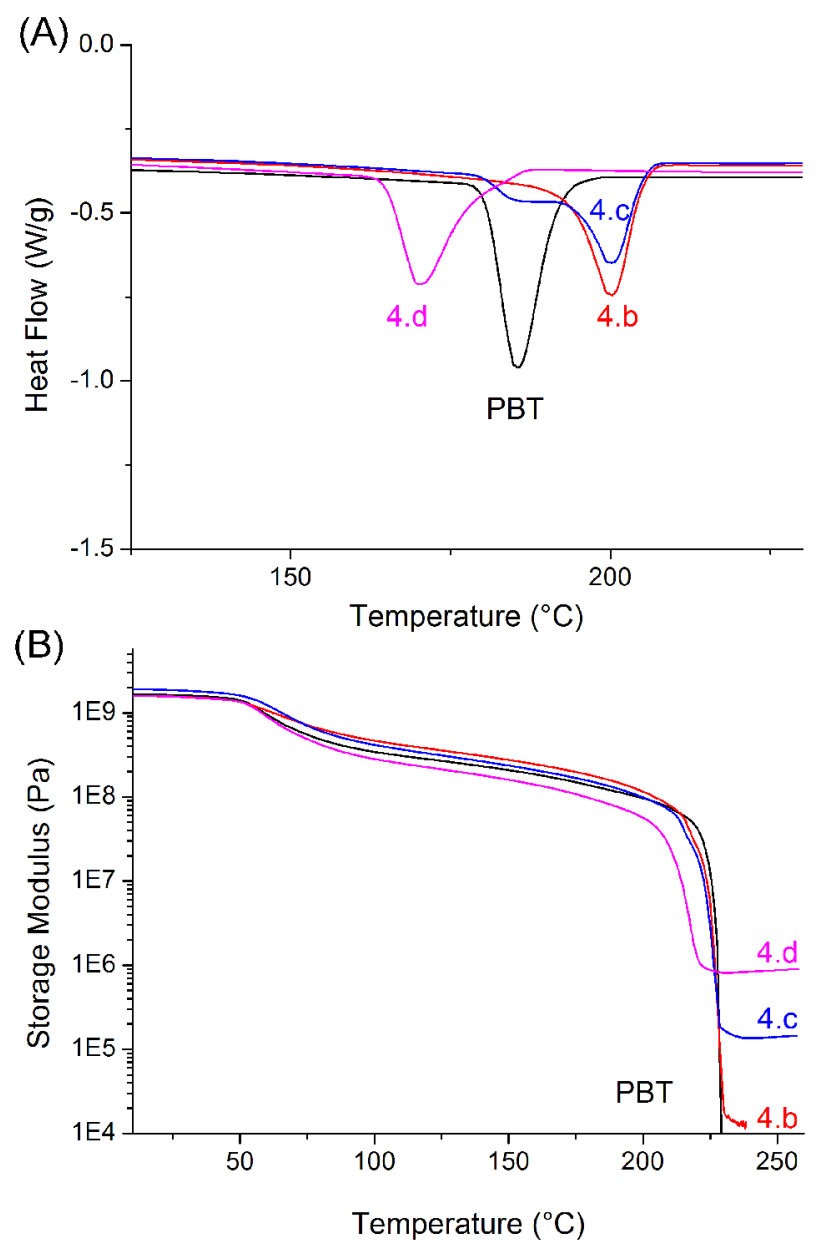

Figure 4: (A) DSC traces obtained on cooling of the pristine and modified PBTs. (B) DMTA analysis: $E^{\prime}$ storage modulus of PBT (black) and compounds $\mathbf{4 b - 4 d}$ (green).

In the vicinity of the glass transition and melting temperatures, all DMTA traces show welldefined drops of $E$ ' similar to those observed in PBT. But in contrast to pristine PBT, compounds $\mathbf{4 c - 4 d}$ show a non-vanishing elastic modulus above $T_{\mathrm{m}}$ at the level of $100 \mathrm{kPa}$ to 1 
$\mathrm{MPa}$, characteristic of an elastomeric substance, which is another confirmation of crosslinking.

As for elastomeric properties, data presented in Figures $3 \mathrm{~A}$ and $4 \mathrm{~B}$ demonstrate that by adjusting the characteristics of the starting material and stoichiometry one can vary at will the duration of the pre-gel period and the stiffness of the final network.

\subsection{Model reactions}

The kinetics of reactions that are likely to occur during extrusion were investigated by using FTIR spectroscopy in ATR mode. We chose $200{ }^{\circ} \mathrm{C}$ as a compromise between conditions close to the usual extrusion temperatures and the possibility to measure quick variations with a semiconductor IR detector. Månson et al. used model molecules to investigate the reactivity of poly(ethylene terephthalate) (PET) end-groups with a multi-epoxy without any catalyst. ${ }^{45}$ They observed that the reaction between the $-\mathrm{COOH}$ and epoxy groups is fast and effective, whereas the reaction between the - $\mathrm{OH}$ and epoxy groups appeared less efficient. Testud et al. investigated the polytransesterification of multifunctional hydroxyester monomers in the presence of various catalysts. ${ }^{46}$ They found that $\mathrm{Zn}$ (II) efficiently catalyze transesterification and identified etherification through dehydration of alcohols as a possible side reaction. The model molecules used in our study are depicted in Table S1. 4-Heptyl benzoic acid was selected because of its low melting temperature $\left(98{ }^{\circ} \mathrm{C}\right)$, low volatility and high compatibility with the epoxy resin. Bisphenol-A bis(2,3-dihydroxypropyl) ether was chosen to mimic the terminal hydroxyl functionalities. For the epoxy model, we used the same compound as in extrusion experiments, namely epoxy $\mathrm{n}=0.03$, which practically does not contain hydroxyl groups. To investigate the role of hydroxyl side groups that could be formed during addition reactions, we used the oligo(bisphenol A-co-epichlorohydrin) prepolymer epoxy $(n=2.4)$, which has a $[\mathrm{OH}] /$ epoxy ratio of approximately 1.2. In all model reaction studies the catalyst concentration was fixed at $5 \mathrm{~mol} \%$. Reactions were followed by measuring the epoxy signal at $910 \mathrm{~cm}^{-1}$, the absorbance was normalized with respect to its initial value. Epoxy + acid

addition reactions in the presence of imidazole $e^{42,47-51}$ and $\mathrm{Zn}(\mathrm{II})^{48,50,51}$ catalysts were investigated. Here, we additionally focus on understanding of the effect of hydroxyl groups on these reactions. 
(A)

$\mathrm{Zn}(\mathrm{acac})_{2}$ catalyst

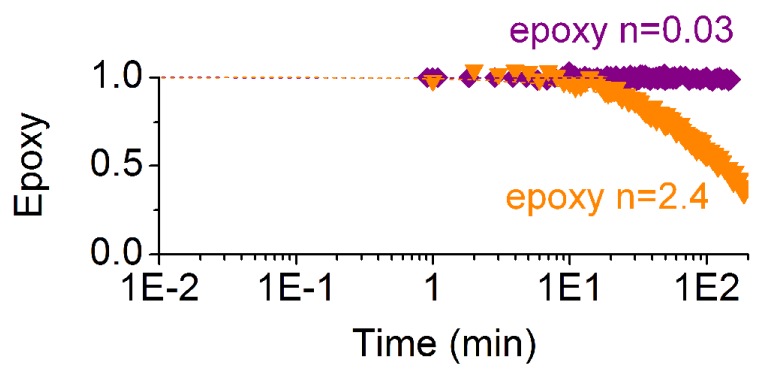

(B)

2-MI catalyst

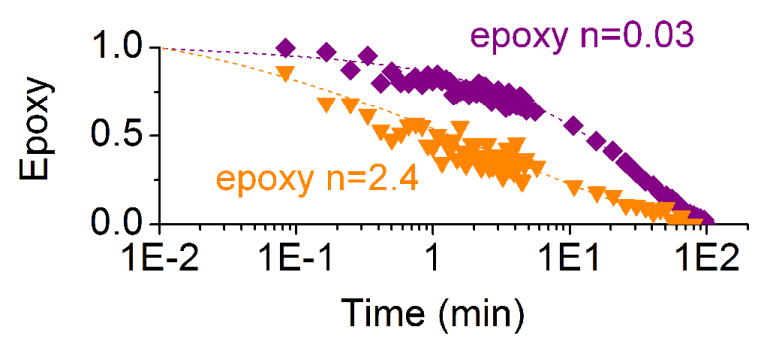

Figure 5 Variation of the epoxy concentration at $200{ }^{\circ} \mathrm{C}$ for two different resins: epoxy n=0.03 (with no $\mathrm{OH}$ groups) and epoxy $\mathrm{n}=2.4$ (with a few $\mathrm{OH}$ groups) after a catalyst $\mathrm{Zn}(\mathrm{acac})_{2}(\mathrm{~A})$ or 2-MI (B) is added.

(A)

$\mathrm{Zn}(\mathrm{acac})_{2}$ catalyst

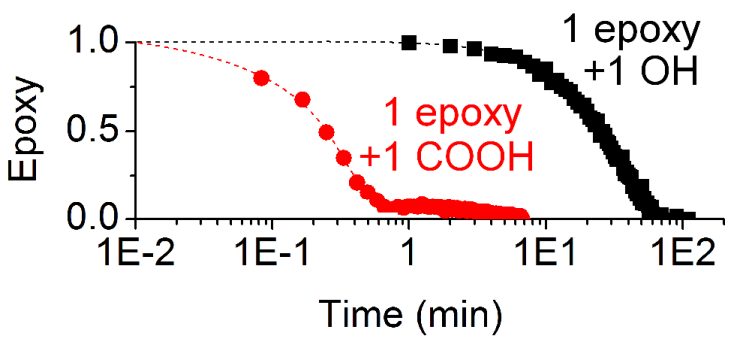

(C)

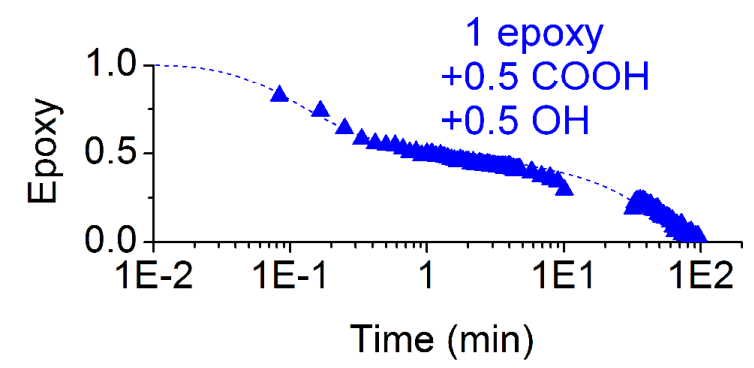

(B) 2-Ml catalyst

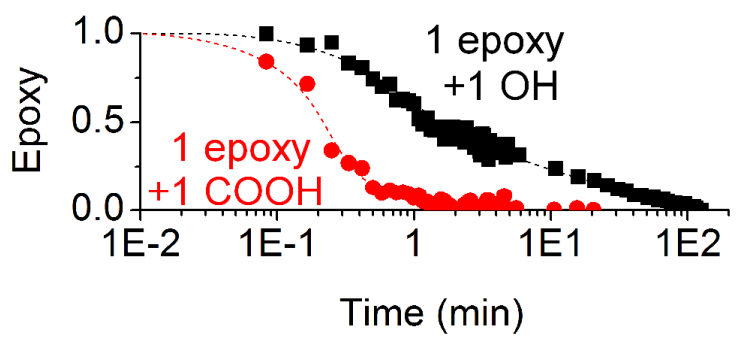

(D)

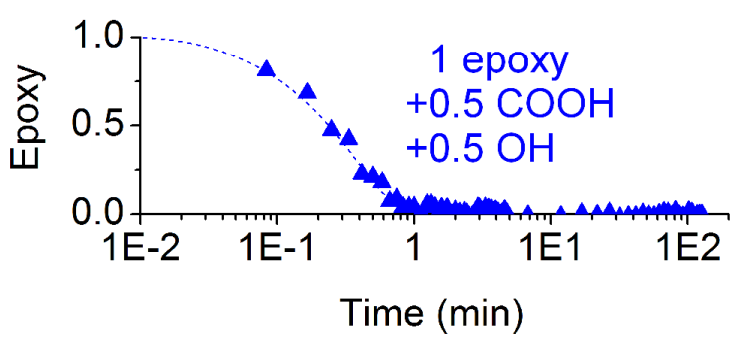

Figure 6 Variation of the epoxy concentration at $200{ }^{\circ} \mathrm{C}$ for the epoxy $n=0.03$ resin mixed with 4-heptyl benzoïc acid and/or bisphenol A bis(2,3-dihydroxypropyl) ether. (A) and (C) catalyzed by Zn (II), (B) and (D) catalyzed by 2-MI. Variation after a catalyst $\mathrm{Zn}(\mathrm{acac})_{2}(\mathrm{~A})$ or 2-MI (B) is added.

Figure 5A shows the evolution of epoxy concentration in the absence of acid groups when $\mathrm{Zn}(\mathrm{acac})_{2}$ is used. In the absence of hydroxyl groups, no reaction takes place. In contrast, when the resin contains - $\mathrm{OH}$ side groups, after 10 minutes, the concentration of epoxy groups decreases. Such a decrease can be attributed to the occurrence of - $\mathrm{OH}+$ epoxy addition reactions. The situation is very different when the 2-MI catalyst is used (Figure 5B). 
Reactions occur even when hydroxyl groups are not present. A possible explanation of these results could be that 2-MI initiates the anionic polymerization of the epoxy resin.

Figure 6A and 6B show the evolution of epoxy groups concentration, as measured by FTIR when acid or alcohol are added in stoichiometric proportions $[\mathrm{COOH}] /[$ epoxy] (resp $[\mathrm{OH}] /[$ epoxy $])=1$. For both $\mathrm{Zn}(\mathrm{II})$ and imidazole catalysts, acid + epoxy reactions are quite rapid. Concerning the alcohol, the decrease of epoxy groups concentration due to alcohol + epoxy addition is faster with 2-MI as catalyst. Figures 6C and 6D show the decay of epoxy groups concentration in the presence of both acid and alcohol at $[\mathrm{COOH}] /[$ epoxy $]=$ $[\mathrm{OH}] /[$ epoxy $]=1 / 2$. Clearly, when the $\mathrm{Zn}(\mathrm{II})$ catalyst is present (Figure 6C) at least two processes take place. First, within a minute, acid groups react with epoxies. The alcohol + epoxy addition is much slower and takes about 100 minutes to be completed. Comparison with Figure 6A shows that the two reactions are practically independent. Since in the presence of 2-MI catalyst, epoxy + alcohol addition can occur at the same time as epoxy + acid addition can occur from the beginning, the situation is more complex (Figure 6D). In the presence of acid, epoxy + alcohol addition seems to be faster, after a few minutes no epoxy groups are left.

In parallel to addition reactions, once ester bonds are formed, transesterification reactions occur. The FTIR spectroscopy does not give any indication about the kinetics of such reactions. Transesterification reactions in the presence of $\mathrm{Zn}(\mathrm{II})$ were studied in detail by gas chromatography coupled with mass spectrometry in references 1, 52-55. In ESI, we included additional measurements for 2-MI by the same technique (Figure S6). At $150{ }^{\circ} \mathrm{C}$, the characteristic time to reach $50 \%$ conversion in the presence of $5 \mathrm{~mol} \% \mathrm{Zn}$ (II) is 1 hour. Using reported value of the activation energy $(130 \mathrm{~kJ} / \mathrm{mol})^{55}$ the estimated time to reach the same conversion at $200{ }^{\circ} \mathrm{C}$ is of about $1.2 \mathrm{~min}$. Hence, we expect that when $\mathrm{Zn}$ (II) catalyst is used, transesterification and formation of cross-links can occur even before all esters bonds are formed. In contrast with 2-MI the time recorded to yield $50 \%$ conversion by transesterification (ESI) is of about $25 \mathrm{~min}$. Therefore, when 2-MI is used, linear or slightly branched chains can be formed first and much longer time is required to make cross-links by transesterification. 


\section{Discussion}

\subsection{Vitrimer network formation}

PBT is an industrial product. Depending on the manufacturer, grade and batch number, the end-group composition can vary. Typically aromatic acid end groups, $-\mathrm{X}=-\mathrm{H}$ in Scheme 1 , are present at a level between 10 to $80 \mathrm{meq} / \mathrm{kg} .{ }^{16}$ The remaining end-groups are essentially primary hydroxy groups coming from the butanediol monomer, $-\mathrm{X}=-\left(\mathrm{CH}_{2}\right)_{4} \mathrm{OH}$ in Scheme 1 .

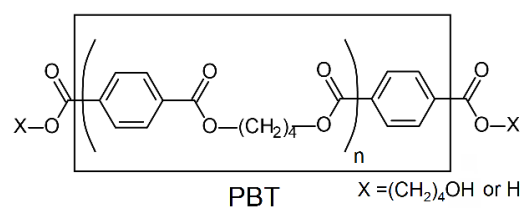

Scheme 1 Chemical structure of PBT.

During processing (extrusion, injection molding, etc) the degradation of hydroxybutyl endgroups is well documented ${ }^{34-39}$ resulting $i$ ) in a small amount of olefinic end groups and $i$ ) to a rearrangement of $-\mathrm{X}=-\left(\mathrm{CH}_{2}\right)_{4} \mathrm{OH}$ into $-\mathrm{X}=\mathrm{H}$ end groups through THF elimination. This second, more important degradation reaction results in an increase of the carboxylic acid endgroup fraction. During extrusion of PBT in the absence of any additive (black squares in Figure 2) the number of acid groups increases. Figure 2A indicates that in the conditions used here at $270{ }^{\circ} \mathrm{C}$ after 10 minutes the increase of acid concentration is approx. $10 \%$ the initial concentration.

The reactive mixing of PBT with diepoxides without added catalyst has been extensively studied. It was found that chain extension can occur. ${ }^{43-44}$ Cross-linking was only reported for high epoxy content and very long reaction times. Our study of - $\mathrm{COOH}$ and -OH concentrations during the reaction without added catalyst (Figure 2A and 2B, green circles) seem to fully confirm the existence of addition reactions (Scheme $2 \mathrm{~A}$ and $2 \mathrm{~B}$ ). The axial force in extrusion (Figure 2C) did not increase substantially and samples after mixing for $10 \mathrm{~min}$ were soluble demonstrating the absence of gelation. 


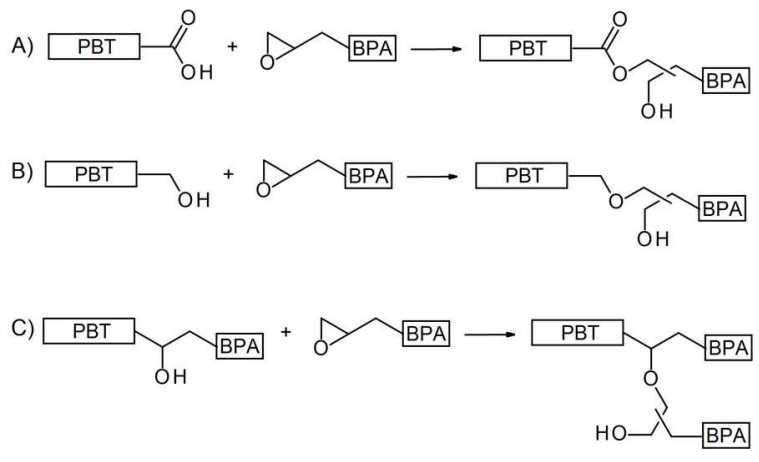

Scheme 2: Illustration of possible addition reactions during reactive mixing of PBT with epoxides: (A) esterification of carboxyl end groups and (B) etherification of hydroxyl end groups. (C) Branching from the secondary hydroxyl groups produced from reactions (A) and (B).

In the presence of catalysts, the situation is more complex (Figure 2). During the mixing the axial force increases indicating the increase of viscoelasticity of the mixture (Figure 2C). When 2-MI is used as a catalyst, (Figure 2, open blue triangles) the increase of axial force is moderate. The consumption of $-\mathrm{COOH}$ groups and increase of $-\mathrm{OH}$ groups show that chain extension through addition reactions (scheme 2A-2B) occur. In principle branching and crosslinking from lateral hydroxyl groups produced during addition reactions could also occur (Scheme 2C). Solubility tests show that after mixing all samples were soluble (Table 2). We conclude that 2-MI catalyst is very efficient to promote esterification and etherification. However, it is not very efficient to promote transesterification. As a result, it is not efficient to promote formation of a permanent network.

In contrast to 2-MI, when $\mathrm{Zn}$ (II) catalyst is used, a particularly abrupt increase of the axial force is observed after a few minutes of mixing. The solubility studies demonstrate formation of a permanent network (Table 2). The study of $-\mathrm{COOH}$ and $-\mathrm{OH}$ variations (Figure $2 \mathrm{~A}$ and 2B) seem to indicate that $\mathrm{Zn}$ (II) promotes chain extension less efficiently than 2-MI. Studies of model molecules confirm this observation. They also indicate that $\mathrm{Zn}$ (II) promotes fast transesterification. The increase of axial force, an indication of cross-linking, seem to occur only when a large fraction of the initially present - $\mathrm{COOH}$ groups is consumed. Addition reactions lead to formation of both ester bonds and lateral hydroxyl groups. As a result, $\mathrm{Zn}$ (II) catalyst is able to induce cross-linking (Scheme 3). The gelation transition can be controlled by the amount of diepoxy present in the mixture. 


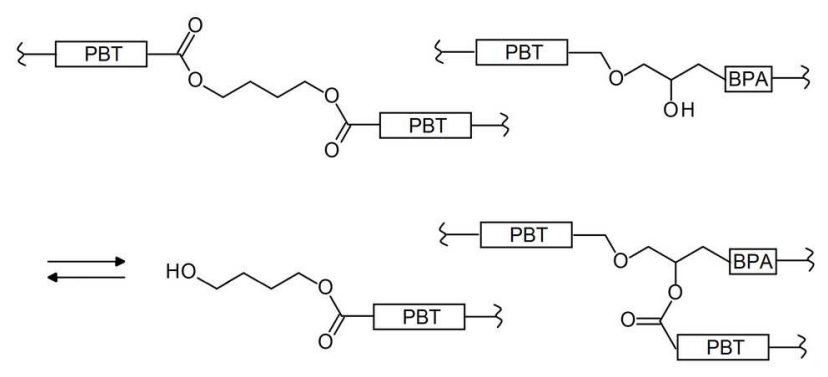

Scheme 3 Illustration of the transesterification towards the formation of a new end-group.

Eventually, a dehydration of alcohols reaction that produces ether bridges could be also evoked. When reacting alcohols and esters in bulk in the presence of $\mathrm{Zn}$ (II) catalyst, Testud et al. observed minor formation of ethers byproducts even though vacuum was applied and stoichiometric conditions were favourable: ${ }^{46}[\mathrm{OH}]>5$ eq./kg and $[\mathrm{OH}] /[$ ester $]>2$. In our case, howver, monitoring of $[\mathrm{OH}]$ gives concentrations not exceeding $100 \mathrm{meq} / \mathrm{g}$, i.e. an $[\mathrm{OH}] /[$ ester] ratio of the order of 0.01 . It is therefore unlikely that dehydration could play an important role. Still, for long reaction times when transesterification is not catalyzed, it could eventually contribute to some cross-linking.

\subsection{Vitrimer network properties}

Reactive mixing of diepoxy and PBT polymers yields permanent networks when mixing is performed in the presence of $\mathrm{Zn}$ (II) catalyst. The solubility tests indicate that cross-linking degree increases when the diepoxy fraction is increased. For example, when the fraction of DGEBA varies from 1.2 to $3.6 \mathrm{wt} \%$, the insoluble fraction increases from 4 to $75 \mathrm{wt} \%$. The increase of cross-linking density with diepoxy fraction is also confirmed by the DMTA experiments at $1 \mathrm{~Hz}$. Above the melting temperature a plateau modulus is observed for high diepoxy contents and it varies between 0.15 to $0.8 \mathrm{MPa}$ when the diepoxy fraction varies from 1.7 to $3.6 \mathrm{wt} \%$.

It is not necessary to carry out the reactive mixing step to complete reaction. Isothermal curing after a short reactive mixing time at temperatures above the melting temperature can be used to increase the cross-linking degree as demonstrated by rheology and solubility experiments (Figure 3). These experiments combined with kinetic studies (Figure 2) show that the molecular weight of the precursor PBT gives an additional handle to control the cross- 
linking degree. For the high molecular weight PBT, the number of $-\mathrm{OH}$ and $-\mathrm{COOH}$ groups is low and the same molar fraction of epoxy leads to a less cross-linked material.

Interestingly, cross-linking does not perturb crystallization. The crystallization is fast and the degree of crystallinity is basically maintained (Figure 4A).

In contrast to PBT cross-linked by irradiation, PBT cross-linked by Zn(II) epoxy-vitrimer chemistry can flow above the melting temperature. As an example, Figure 7 shows the stress relaxation results and the variation of viscosity as a function of temperature for compound $\mathbf{4 c}$. Figure 7B shows an Arrhenius dependence $\ln (\eta) \sim 1 / T$, as hitherto observed in vitrimers. The value of the activation energy is of about $140 \mathrm{~kJ} / \mathrm{mol}$.
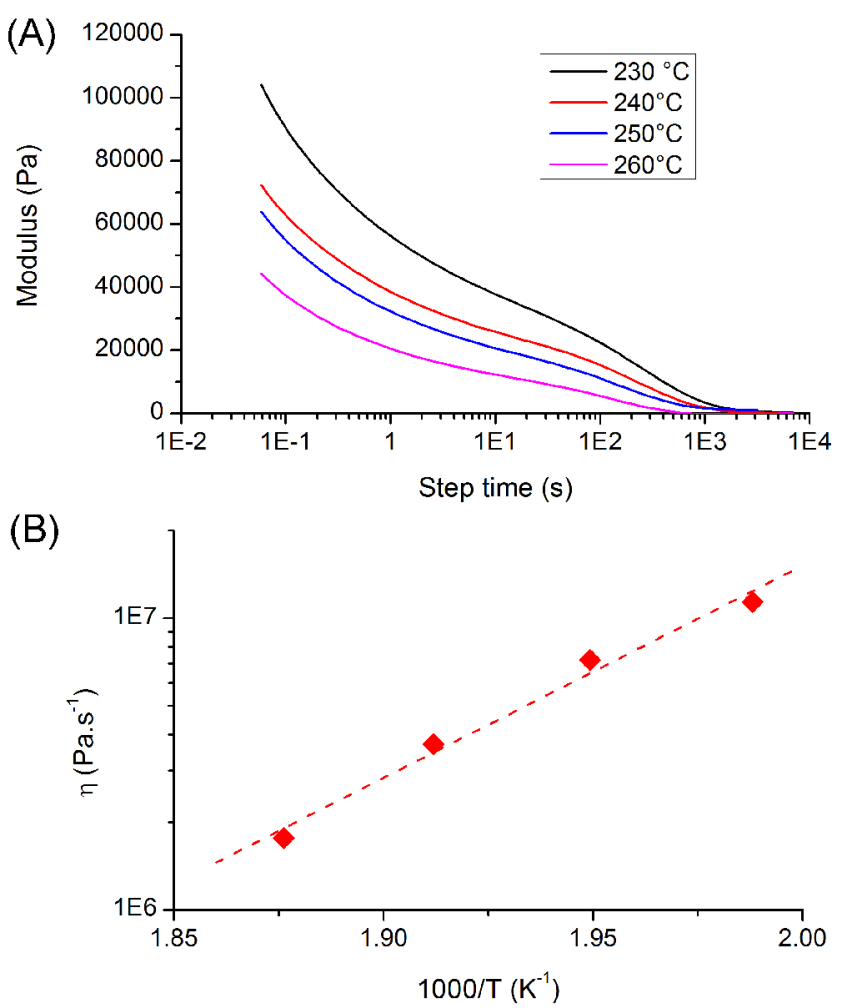

Figure 7 (A) Plots of stress relaxation experiments on compound 4c, (B) Variation of the viscosity as a function of inverse temperature 1000/T showing Arrhenius dependence.

The elastic modulus above $T_{\mathrm{m}}$, viscosity and relaxation time can be tuned by the amount of diepoxy. Thus, the relaxation time at $230{ }^{\circ} \mathrm{C}$ is $500 \mathrm{~s}$ for compound $\mathbf{4 c}$ and $1300 \mathrm{~s}$ for compound 4d. The long relaxation times above the melting temperature bring good dimensional stability to PBT vitrimers. For the PBT with highest cross-linking, compound $\mathbf{4 d}$ the value of viscosity is about $\eta \sim 10^{8} \mathrm{~Pa}$.s at $250{ }^{\circ} \mathrm{C}$. This value is huge in comparison with the viscosity of standard PBT, which ranges from 30 to $900 \mathrm{~Pa} . \mathrm{s}$ at $250{ }^{\circ} \mathrm{C} .{ }^{16}$ The frequency sweep experiments illustrate nicely this difference (Figure 8A). At $250{ }^{\circ} \mathrm{C}$, PBT before 
modification, shows the characteristics of a non-entangled polymer melt. The value of viscosity, inferred from the $G^{\prime \prime}(\omega) \sim \omega$ terminal regime variation is approx. 200 Pa.s. At the same temperature, the vitrimer PBT (compound 4d) shows elastomeric plateau properties with no evidence of any terminal regime down to an angular frequency of $10^{-2} \mathrm{~s}^{-1}$. Indeed, for this compound, the relaxation time given by stress relaxation experiments is much larger than $100 \mathrm{~s}$

Figures $8 \mathrm{~B}$ and $8 \mathrm{C}$ illustrate the good dimensional stability of vitrimers in comparison with standard PBT. We show the appearance of compression-molded coin-sized specimens made of these two materials after a residence times of 3 minutes and 30 minutes respectively in an oven at $250{ }^{\circ} \mathrm{C}$ in air.

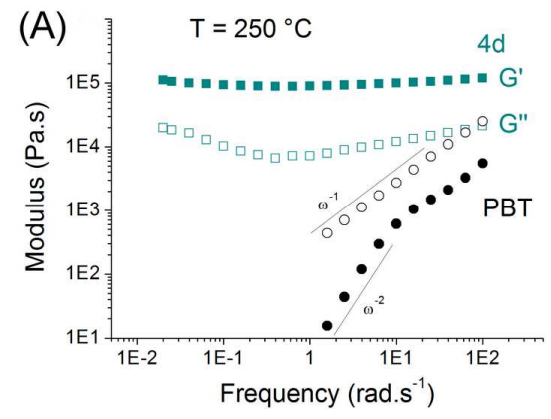

(B)

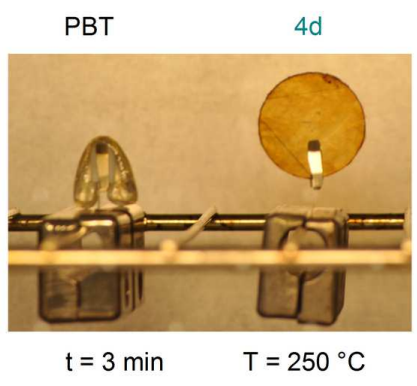

(C)

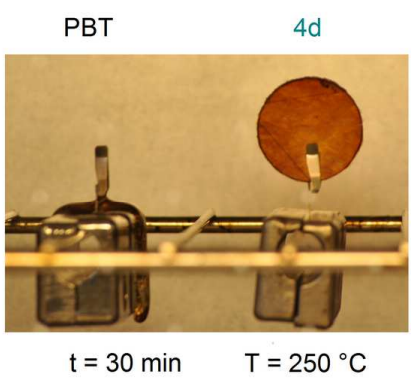

Figure 8 (A) Angular frequency dependence of storage modulus G' (filled symbol) and loss modulus G" (open symbols) at $250{ }^{\circ} \mathrm{C}$ for PBT (circles), compound $\mathbf{4 d}$ (squares). (B) Appearance of PBT and compound $4 \mathbf{d}$ disks after $3 \mathrm{~min}$ in an oven at $250^{\circ} \mathrm{C}$. (D) Appearance of PBT and compound $\mathbf{4 d}$ disks after $30 \mathrm{~min}$ in an oven at 250 ${ }^{\circ} \mathrm{C}$.

After $3 \mathrm{~min}$ in the oven, both samples have become transparent but pristine PBT immediately flows, whereas the shape of the PBT vitrimer part is retained. Under its own weight a coinsized specimen undergoes a stress of about $\rho . g . h \sim 100 \mathrm{~Pa}$, where $\rho$ is the density of the polymer, $g$ the gravitational acceleration and $h$ the height of the specimen. With a viscosity of $200 \mathrm{~Pa}$.s the expected strain rate $\dot{\gamma}=\sigma / \eta$ is of about $0.5 \mathrm{~s}^{-1}$. Thus, without surprise, the coin shape is not recognizable after 3 minutes. For the vitrimer PBT part, however, the strain rate is approx. $\dot{\gamma}=10^{-6} \mathrm{~s}^{-1}$ and deformation is hardly detectable on this time scale. The fixed shape is also a demonstration that the compression-molded part was thoroughly relaxed. The same two samples after 30 minutes are shown in Figure 8C. Pristine PBT has dripped outside the framing field, but the vitrimer PBT is still in place. One can see in the picture that after 30 minutes at $250{ }^{\circ} \mathrm{C}$ in some oxidation took place, as shown by the brownish color, but interestingly the shape of the specimen is not much altered. Thus, similarly to radiation cross- 
linked PBT, PBT cross-linked with the help of epoxy-vitrimer chemistry can handle high temperatures for a relatively long time, whereas the standard PBT flows immediately above the melting temperature.

\section{Conclusion}

Research and development of vitrimers confronts two challenges. The first challenge concerns the translation of unique combination of vitrimer properties into novel materials and applications. Literature on design of weldable long fiber composites $^{56-58}$ and nanocomposites, ${ }^{59}$ photo-responsive carbon-nanotube composites, ${ }^{60-61} \mathrm{UV}$-curable thiol-ene vitrimers for patterning and nanoimprint lithography, ${ }^{62}$ moldable and multi-functional liquidcrystalline elastomer actuators, ${ }^{63,64}$ shape memory polymer networks ${ }^{65-69}$ show some interesting directions and potential uses. The second challenge is to develop dynamic covalent chemistries that will allow bringing vitrimer properties to currently produced thermoplastics and thermosets. Developments in the area of fully bio-based vitrimers, ${ }^{2,10,70}$ amorphous polyesters, ${ }^{4}$ polyurethanes and polyureas ${ }^{7,12,69,71,72}$ or of polymers with C-C backbones ${ }^{13,73}$ are promising examples. In this article, we have developed a semi-crystalline PBT vitrimer via an industrial process, reactive mixing, starting from standard base materials, i.e. PBT thermoplastic, and an epoxy resin. Epoxy chemistry is particularly convenient as it allows chain extension and branching without release of small molecules. In principle, reacting PBT with multifunctional alcohols could also yield a PBT dynamic network. However, to advance the reaction, small molecules have to be eliminated and a different synthetic route, solid-state polymerization (SSP), is better adapted for this purpose. ${ }^{74}$

The PBT vitrimers obtained through reactive mixing with diepoxides retain the properties of PBT thermoplastics such as a high degree of crystallinity, while they gain the properties of a cross-linked material such as dimensional stability above melting temperature. Indeed, in contrast to PBT thermoplastics, above melting temperature PBT vitrimers exhibit a rubbery elastic plateau and relax stresses only after a long time. The rubbery plateau and stress relaxation times can be tuned by adjusting the molecular weight of the starting materials and the amount of cross-linker used. The same is true for PBT vitrimers obtained by SSP and both types of materials were found to show an Arrhenius dependance of viscosity with very close $E_{\mathrm{a}}$ values. Interestingly, PBT vitrimers can be obtained within a few minutes by reactive 
mixing whereas several hours are necessary by SSP. When reactions are completed, both types of materials show a slight yellowish aspect, due to the presence of the $\mathrm{Zn}$ (II) catalyst.

We have shown that alcohol-epoxy and acid-epoxy addition reactions and transesterification reactions, which determine the relative kinetics of chain extension, chain branching and crosslinking can be conveniently controlled by the choice of a catalyst, the molecular weight of precursor PBT chains and the diepoxide content. In terms of industrial processing, such a control provides tools to combine an optimal and versatile manner of extrusion, object molding and thermal post-curing steps. In particular, it is possible to find conditions that avoid long residence time in the extruder and high viscosity during injection molding.

In conclusion, vitrimer epoxy based chemistry yields a versatile method to permanently crosslink semi-crystalline PBT thermoplastics without a need to use radiation chemistry facilities. Cross-linked PBT vitrimers can be reshaped and welded. Advantageous properties of PBT vitrimers bode well for their industrial applications for example in electric appliances and electronics for which keeping the integrity of electrical insulation in case of accidental overheating is essential.

\section{References}

(1) Montarnal, D.; Capelot, M.; Tournilhac, F.; Leibler, L. Silica-Like Malleable Materials from Permanent Organic Networks. Science 2011, 334 (6058), 965-968.

(2) Lu, Y.-X.; Tournilhac, F.; Leibler, L.; Guan, Z. Making Insoluble Polymer Networks Malleable via Olefin Metathesis J. Am. Chem. Soc. 2012, 134 (20), 8424-8427.

(3) Altuna, F. I.; Pettarin, V.; Williams, R. J. Self-healable polymer networks based on the crosslinking of epoxidised soybean oil by an aqueous citric acid solution. Green Chem. 2013, 15 (12), 3360-3366.

(4) Brutman, J. P.; Delgado, P. A.; Hillmyer, M. A. Polylactide Vitrimers. ACS Macro Lett. 2014, 3 (7), 607-610.

(5) Imbernon, L.; Oikonomou, E. K.; Norvez, S.; Leibler, L. Chemically crosslinked yet reprocessable epoxidized natural rubber via thermo-activated disulfide rearrangements. Polym. Chem., 2015, 4271-4278.

(6) Romano, F.; Sciortino, F. Switching Bonds in a DNA Gel: An All-DNA Vitrimer. Phys. Rev. Letters 2015, 114, 078104-1-5.

(7) Denissen, W.; Rivero, G.; Nicolaÿ, R.; Leibler, L.; Winne, J. M.; Du Prez, F. E. Vinylogous Urethane Vitrimers. Adv. Funct. Mat. 2015, 25, 2451-2457.

(8) Obadia, M. M.; Mudraboyina, B. P.; Serghei, A.; Montarnal, D.; Drockenmuller, E. Reprocessing and Recycling of Highly Cross-Linked Ion-Conducting Networks through Transalkylation Exchanges of C-N Bonds. J. Am. Chem. Soc. 2015, 137 (18), 60786083. 
(9) Imbernon, L.; Norvez, S.; Leibler, L. Stress Relaxation and Self-Adhesion of Rubbers with Exchangeable Links. Macromolecules, 2016, 49, 2172-2178.

(10) Imbernon, L.; Norvez, S. From Landfilling to Vitrimer Chemistry in Rubber Life Cycle. Eur. Polym. J. 2016, 82, 347-376.

(11) Chen, Q.; Yu, X.; Pei, Z.; Yang, Y.; Wei, Y.; Ji, Y. Multi-stimuli responsive and multifunctional oligoaniline-modified vitrimers. Chem. Sci. 2017, 8, 724-733.

(12) Denissen, W.; Droesbeke, M.; Nicolaÿ, R.; Leibler, L.; Winne, J. M.; Du Prez, F. E. Chemical control of the viscoelastic properties of vinylogous urethane vitrimers. Nature Commun. 2017, 8, 14857-1-7.

(13) Röttger, M; Domenech, T.; van der Weegen, R.; Breuillac, A.; Nicolaÿ, R.; Leibler, L. High-performance vitrimers from commodity thermoplastics through dioxaborolane metathesis. Science 2017, 356, 62-65.

(14) Fakirov, S. Handbook of thermoplastic polyesters: homopolymers, copolymers, blends, and composites; Wiley-VCH Verlag GmbH: Weinheim, 2002.

(15) Bernnat, Anka; Eibeck, Peter; Dirlenbach, Jan. Polybutylenterephtalat (PBT). Kunststoffe 2013, 10, 106-110.

(16) Gallucci, R. R.; Patel, B. R. In Modern Polyesters: Chemistry and Technology of Polyesters and Copolyesters; Scheirs, J.; Long, T. E., Eds.; John Wiley \& Sons: Chichester, 2003; pp 293-322.

(17) Antić, V. V.; Pergal, M. V. In Handbook of Engineering and Specialty Thermoplastics: Polyethers and Polyesters Volume 3; Thomas, S.; Visakh, P. M., Eds; John Wiley \& Sons: Hoboken, 2011; pp 127-180.

(18) Miller, S. Macrocyclic polymers from cyclic oligomers of poly(butylene terephthalate). Ph.D. dissertation, University of Massachusetts, Amherst, 1998, p 139.

(19) Wypych, G. Handbook of polymers; ChemTec Publishing: Oxford, 2012.

(20) Cleland, M. R.; Parks, L. A.; Cheng, S. Applications for radiation processing of materials. Nucl. Instrum. Methods Phys. Res. Sect. B Beam Interact. Mater. At. 2003, 208, 66-73.

(21) Rouif, S. Radiation cross-linked polymers: Recent developments and new applications. Nucl. Instrum. Methods Phys. Res. Sect. B Beam Interact. Mater. At. 2005, 236 (1), 6872.

(22) Mizera, A.; Manas, M.; Manas, D.; Holik, Z.; Stanek, M.; Navrátil, J.; Bednarik, M. Tensile Behaviour of Modified PBT by Radiation Cross-Linking. Adv. Mat. Res. 2014, 1025, 256-260.

(23) Hooshangi, Z.; Feghhi, S. A. H.; Sheikh, N. The effect of electron-beam irradiation and halogen-free flame retardants on properties of poly butylene terephthalate. Radiat. Phys. Chem. 2015, 108, 54-59.

(24) Koning, C.; Van Duin, M.; Pagnoulle, C.; Jerome, R. Strategies for Compatibilization of Polymer Blends. Prog. Polym. Sci. 1998, 23 (4), 707-757.

(25) Orr, C. A.; Cernohous, J. J.; Guegan, P.; Hirao, A.; Jeon, H. K.; Macosko, C. W. Homogeneous reactive coupling of terminally functional polymers. Polymer 2001, 42 (19), 8171.

(26) Pernot, H.; Baumert, M.; Court, F.; Leibler, L. Design and properties of co-continuous nanostructured polymers by reactive blending. Nat. Mater. 2002, 1 (1), 54-58.

(27) Jeon, H. K.; Macosko, C. W.; Moon, B.; Hoye, T. R.; Yin, Z. Coupling Reactions of End- vs Mid-Functional Polymers. Macromolecules 2004, 37 (7), 2563-2571.

(28) Ruzette, A.-V.; Leibler, L. Block copolymers in tomorrow's plastics. Nat. Mater. 2005, $4(1), 19-31$. 
(29) Freluche, M.; Iliopoulos, I.; Flat, J.-J.; Ruzette, A.-V.; Leibler, L. Self-organized materials and graft copolymers of polymethylmethacrylate and polyamide- 6 obtained by reactive blending. Polymer 2005, 46 (17), 6554-6562.

(30) Corte, L.; Rebizant, V.; Hochstetter, G.; Tournilhac, F.; Leibler, L. Toughening with Little Stiffness Loss: Polyamide Filled with ABC Triblock Copolymers. Macromolecules 2006, 39 (26), 9365-9374.

(31) Ward, I. M. The measurement of hydroxyl and carboxyl end groups in polyethylene terephthalate. Trans. Faraday Soc. 1957, 53, 1406-1412.

(32) Patterson, D.; Ward, I. M. The assignment of the carboxyl and hydroxyl absorptions in the infra-red spectrum of polyethylene terephthalate. Trans. Faraday Soc. 1957, 53, 291-294.

(33) Kosky, P. G.; McDonald, R. S.; Guggenheim, E. A. Determination of end-group concentrations and molecular weight of poly(butylene terephthalate) by solid-state fourier transform infrared spectroscopy. Polym. Eng. Sci. 1985, 25 (7), 389-394.

(34) Bikiaris, D. N.; Karayannidis, G. P. E. Effect of carboxylic end groups on thermooxidative stability of PET and PBT. Polym. Degrad. Stab. 1999, 63 (2), 213-218.

(35) Lum, R. M. Thermal decomposition of poly(butylene terephthalate). J. Polym. Sci. Polym. Chem. Ed. 1979, 17 (1), 203-213.

(36) Passalacqua, V.; Pilati, F.; Zamboni, V.; Fortunato, B.; Manaresi, P. Thermal degradation of poly(butylene terephthalate). Polymer 1976, 17 (12), 1044-1048.

(37) Pilati, F.; Manaresi, P.; Fortunato, B.; Munari, A.; Passalacqua, V. Formation of poly(butylene terephthalate): Secondary reactions studied by model molecules. Polymer 1981, 22 (11), 1566-1570.

(38) Devroede, J.; Duchateau, R.; Koning, C. E.; Meuldijk, J. The Synthesis of Poly(butylene terephthalate) from Terephthalic Acid, Part I: The Influence of Terephthalic Acid on the Tetrahydrofuran Formation. J. Appl. Polym. Sci. 2009, 114 (4), 2435-2444.

(39) Devroede, J.; Duchateau, R.; Koning, C. E. The synthesis of poly(butylene terephthalate) from terephthalic acid, part II: Assessment of the first stage of the polymerization process. J. Appl. Polym. Sci. 2009, 114 (4), 2427-2434.

(40) Heise, M. S.; Martin, G. C.; Gotro, J. T. Analysis of gel formation in imidazolecatalyzed epoxies. Polym. Eng. Sci. 1992, 32 (8), 529-534.

(41) Heise, M. S.; Martin, G. C. Curing mechanism and thermal properties of epoxyimidazole systems. Macromolecules 1989, 22 (1), 99-104.

(42) Montarnal, D.; Tournilhac, F.; Hidalgo, M.; Leibler, L. Epoxy-Based Networks Combining Chemical and Supramolecular Hydrogen-Bonding Crosslinks. J. Polym. Sci. Part A Polym. Chem. 2010, 48 (5), 1133-1141.

(43) Bikiaris, D. N.; Karayannidis, G. P. Chain extension of polyesters PET and PBT with two new diimidodiepoxides. II. J. Polym. Sci. Part A Polym. Chem. 1996, 34 (7), 13371342.

(44) Xie, F.; Zhou, C.; Yu, W.; Wu, D. Study on the reaction kinetics between PBT and epoxy by a novel rheological method. Eur. Polym. J. 2005, 41 (9), 2171-2175.

(45) Japon, S.; Boogh, L.; Leterrier, Y.; Månson, J.-A. Reactive processing of poly(ethylene terephthalate) modified with multifunctional epoxy-based additives. Polymer 2000, 41 (15), 5809-5818.

(46) Testud, B.; Pintori, D.; Grau, E.; Taton, D.; Cramail, H. Hyperbranched polyesters by polycondensation of fatty acid-based ABn-type monomers. Green Chem. 2017, 19, 259269.

(47) Pire, M.; Lorthioir, C.; Oikonomou, E. K.; Norvez, S.; Iliopoulos, I.; Le Rossignol, B.; Leibler, L. Imidazole-accelerated crosslinking of epoxidized natural rubber by 
dicarboxylic acids : a mechanistic investigation using NMR spectroscopy. Polym. Chem. 2012, 3 (4), 946-953.

(48) Pire, M.; Norvez, S.; Iliopoulos, I.; Le Rossignol, B.; Leibler, L. Imidazole-promoted acceleration of crosslinking in epoxidized natural rubber/dicarboxylic acid blends. Polymer 2011, 52 (23), 5243-5249.

(49) Sordo, F.; Mougnier, S.-J.; Loureiro, N.; Tournilhac, F.; Michaud, V. Design of SelfHealing Supramolecular Rubbers with a Tunable Number of Chemical Cross-Links Macromolecules 2015, 48 (13), 4394-4402.

(50) Blank, W. J.; He, Z. A.; Picci, M. Catalysis of the epoxy-carboxyl reaction. J. Coat. Technol. 2002, 74 (926), 33-41.

(51) Merfeld, G.; Molaison, C.; Koeniger, R.; Acar, A. E.; Mordhorst, S.; Suriano, J.; Irwin, P.; Warner, R. S.; Gray, K.; Smith, M.; others. Acid/epoxy reaction catalyst screening for low temperature $\left(120^{\circ} \mathrm{C}\right)$ powder coatings. Prog. Org. Coat. 2005, 52 (2), 98-109.

(52) Capelot, M.; Unterlass, M. M.; Tournilhac, F.; Leibler, L. Catalytic Control of the Vitrimer Glass Transition. ACS Macro Lett. 2012, 1 (7), 789-792.

(53) Capelot, M.; Montarnal, D.; Tournilhac, F.; Leibler, L. Metal-Catalyzed Transesterification for Healing and Assembling of Thermosets. J. Am. Chem. Soc. 2012, 134 (18), 7664-7667.

(54) Demongeot, A.; Mougnier, S.-J.; Okada, S.; Soulié-Ziakovic, C.; Tournilhac, F. Coordination and Catalysis of Zn2+ in Epoxy-Based Vitrimers. Polym. Chem. 2016, 7, 4486-4493.

(55) Capelot M. Chimie de Polycondensation, Polymères Supramoléculaires et Vitrimères. Ph.D. dissertation, University Pierre and Marie Curie, Paris, 2013, p 91.

(56) Chabert, E.; Vial, J.; Cauchois, J.-P.; Mihaluta, M.; Tournilhac, F. Multiple Welding of Long Fiber Epoxy Vitrimer Composites. Soft Matter 2016, 12, 4838-4845.

(57) de Luzuriaga, A. R.; Martin, R.; Markaide, N.; Rekondo, A.; Cabañero, G.; Rodríguez, J.; Odriozola, I. Epoxy resin with exchangeable disulfide crosslinks to obtain reprocessable, repairable and recyclable fiber-reinforced thermoset composites. Mater. Horiz. 2016, 3 (3), 241-247.

(58) Taynton, P.; Ni, H.; Zhu, C.; Yu, K.; Loob, S.; Jin, Y.; Qi, H. J.; Zhang, W. Repairable Woven Carbon Fiber Composites with Full Recyclability Enabled by Malleable Polyimine Networks. Adv. Mater. 2016, 28, 2904-2909.

(59) Legrand, A.; Soulié-Ziakovic, C. Silica-Epoxy Vitrimer Nanocomposites. Macromolecules, 2016, 49 (16), 5893-5902.

(60) Yang, Y.; Pei, Z.; Zhang, X.; Tao, L.; Wei, Y.; Ji, Y. Carbon nanotube-vitrimer composite for facile and efficient photo-welding of epoxy. Chem. Sci. 2014, 5 (9), 34863492.

(61) Yang, Y.; Pei, Z.; Li, P.; Wei, Y.; Ji, Y. Making and Remaking Dynamic 3D Structures by Shining Light on Flat Liquid Crystalline Vitrimer Films without a Mold. J. Am. Chem. Soc. 2016, 138, 2118-2121.

(62) Lyon, G. B.; Cox, L. M.; Goodrich, J. T.; Baranek, A. D.; Ding, Y.; Bowman, C. N. Remoldable Thiol-Ene Vitrimers for Photopatterning and Nanoimprint Lithography. Macromolecules 2016, 49, 8905-8913.

(63) Pei, Z.; Yang, Y.; Chen, Q.; Terentjev, E. M.; Wei, Y.; Ji, Y. Mouldable liquidcrystalline elastomer actuators with exchangeable covalent bonds. Nat. Mater. 2014, 13 (1), 36-41.

(64) Li, Y.; Rios, O.; Keum, J. K.; Chen, J.; Kessler, M. R. Photoresponsive Liquid Crystalline Epoxy Networks with Shape Memory Behavior and Dynamic Ester Bonds. ACS Appl. Mater. Interfaces, 2016, 8, 15750-15757. 
(65) Pei, Z.; Yang, Y.; Chen, Q.; Wei, Y.; Ji, Y. Regional Shape Control of Strategically Assembled Multishape Memory Vitrimers. Adv. Mater. 2016, 28, 156-160.

(66) Zhao, Q.; Zou, W.; Luo, Y.; Xie, T. Shape memory polymer network with thermally distinct elasticity and plasticity. Sci. Adv. 2016, 2 (1), e1501297.

(67) Arnebold, A.; Hartwig, A. Fast switchable, epoxy based shape-memory polymers with high strength and toughness. Polymer, 2016, 83, 40-49.

(68) Arnebold, A.; Wellmann, S.; Hartwig, A. Network dynamics in cationically polymerized, crosslinked epoxy resins and its influence on crystallinity and toughness. Polymer, 2016, 91, 14-23.

(69) Zheng, N.; Fang, Z.; Zou, W.; Zhao, Q.; Xie, T. Thermoset Shape-Memory Polyurethane with Intrinsic Plasticity Enabled by Transcarbamoylation. Angew. Chem. Int. Ed. 2016, 55, 11421-11425.

(70) Altuna, F. I.; Hoppe, C. E.; Williams, R. J. J. Shape memory epoxy vitrimers based on DGEBA crosslinked with dicarboxylic acids and their blends with citric acid. RSC Adv. 2016, 6, 88647-88655.

(71) David J. Fortman, D. J.; Brutman, J. P.; Cramer, C. J.; Hillmyer, M. A.; Dichtel, W. R. Mechanically Activated, Catalyst-Free Polyhydroxyurethane Vitrimers. J. Am. Chem. Soc. 2015, 137, 14019-14022.

(72) Yanfeng Zhang, Y.; Ying, H.; Hart, K. R.; Wu, Y.; Hsu, A. J.; Coppola, A. M.; Kim, T. A.; Yang, K.; Sottos, N. R.; White, S. R.; Cheng, J. Malleable and Recyclable Poly(ureaurethane) Thermosets bearing Hindered Urea Bonds. Adv. Mater. 2016, 28, 7646-7651.

(73) Jin, K.; Li, L.; Torkelson, J. M. Recyclable Crosslinked Polymer Networks via One-Step Controlled Radical Polymerization. Adv. Mater. 2016, 28, 6746-6750.

(74) Zhou, Y.; Goossens, J. G. P.; Sijbesma, R. P.; Heuts, J. P. A. Poly(butylene terephthalate)/Glycerol-based Vitrimers via Solid-State Polymerization This journal. 
Graphical Abstract

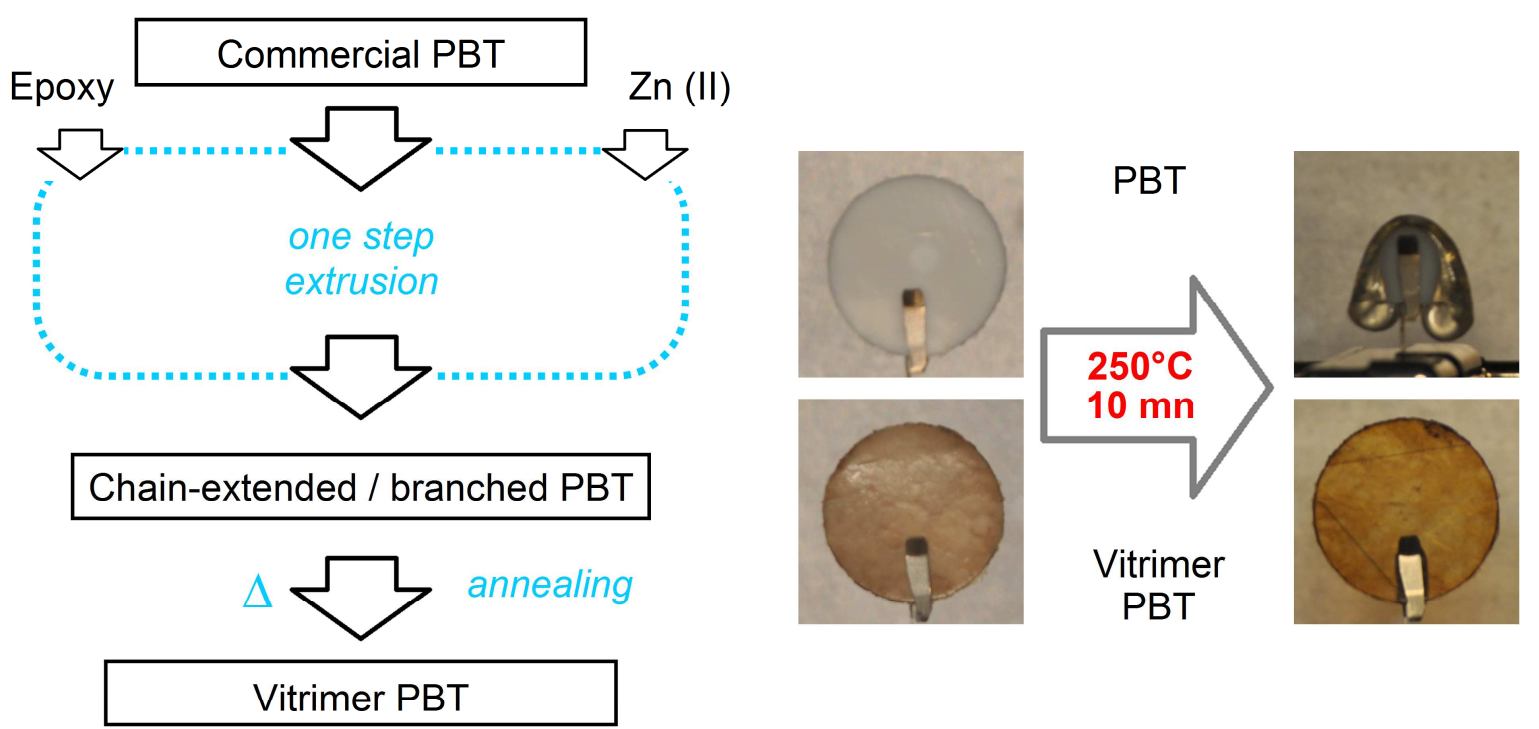

semi-crystalline insoluble reshapable 


\section{Crosslinking of PBT by reactive extrusion using Zn(II) epoxy- vitrimer chemistry}

Adrien Demongeot, ${ }^{\dagger}$ Ramon Groote, ${ }^{\ddagger}$ Han Goossens, ${ }^{\ddagger}$ Theo Hoeks, ${ }^{\ddagger}$ François Tournilhac, ${ }^{,, \dagger}$ Ludwik Leibler ${ }^{*, \dagger}$

${ }^{\dagger}$ Matière Molle et Chimie, UMR 7167 CNRS ESPCI Paris, PSL Research University, 10 rue Vauquelin 75005 Paris, France.

‡ SABIC T\&I, Plasticslaan 1, 4612 PX Bergen op Zoom, the Netherlands.

\section{Supplementary Information}

Synthesis of bisphenol A bis(2,3-dihydroxypropyl) ether<smiles>CC(C)(c1ccc(OCC(O)CO)cc1)c1ccc(OCC(O)CO)cc1</smiles>

Scheme 1 Synthesis of bisphenol A bis(2,3-dihydroxypropyl) ether.

In a $500 \mathrm{~mL}$ two necks round bottom flask attached to a condenser, a solution of sodium hydroxide $(7.26 \mathrm{~g}, 0.18 \mathrm{~mol})$ in water $(120 \mathrm{~mL})$ was placed. With stirring, bisphenol A $(10.3 \mathrm{~g}, 45 \mathrm{mmol})$ were added. The mixture was heated to $80{ }^{\circ} \mathrm{C}$ under a nitrogen atmosphere. Then, 3-chloro-1,2-propanediol (11.4 mL, $0.14 \mathrm{~mol})$ was slowly added dropwise with a purged syringe. Stirring was continued for 16 hours at $80{ }^{\circ} \mathrm{C}$. Subsequently, the solution was allowed to cool down to room temperature. After cooling, a solution of hydrochloric acid $(16.0 \mathrm{~mL}, 0.18 \mathrm{~mol})$ in water $(120 \mathrm{~mL})$ was added and the mixture stirred at $80{ }^{\circ} \mathrm{C}$ for an hour. Again the solution was allowed to cool down to room temperature. The mixture was decanted and the organic phase was extracted in ethyl acetate. This solution was washed three times with $\mathrm{NaCl}$-saturated water $(80 \mathrm{~mL})$ and distilled water $(80 \mathrm{~mL})$, dried over anhydrous magnesium sulfate, and filtered. The obtaining solid was purified by 
chromatography eluting with ethyl acetate. The product was dried in vacuum at $50{ }^{\circ} \mathrm{C}$ for 16 hours. The final product is a white crystalline solid $\left(\mathrm{MP}=86-87^{\circ} \mathrm{C}\right)$.

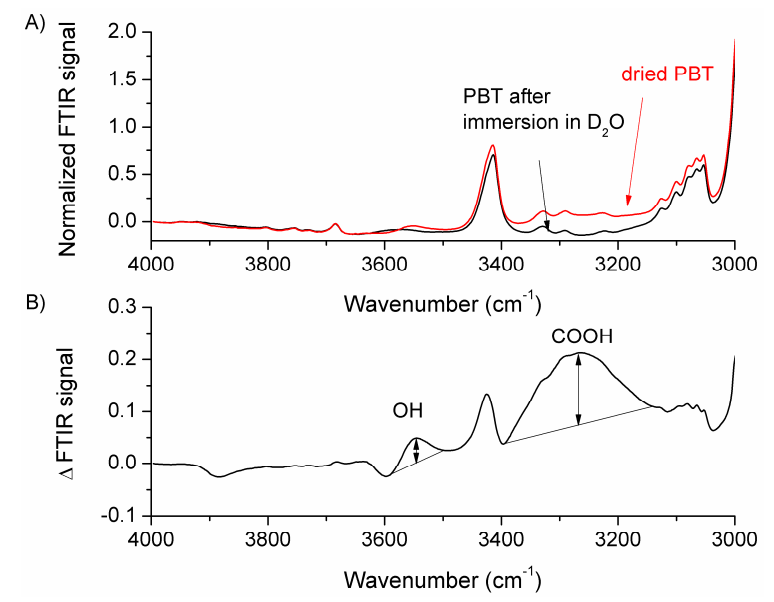

Figure S1 Determination of $[\mathrm{COOH}]$ and $[\mathrm{OH}]$ end-group concentration by IR spectrometry. (A) FTIR spectrum of dried PBT (black) and PBT after immersion in $\mathrm{D}_{2} \mathrm{O}$ (B) FTIR signal difference.

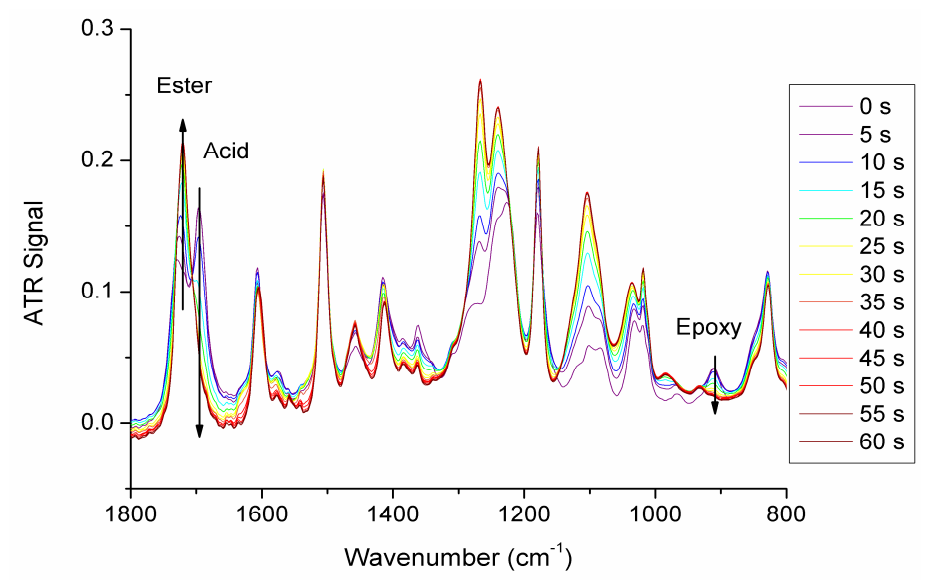

Figure S2 Determination of epoxy consumption during kinetic experiments with model molecules. Example of ATR-IR spectra showing the epoxy-acid addition catalyzed by $\mathrm{Zn}(\mathrm{acac})_{2}$ at $200{ }^{\circ} \mathrm{C}$. Spectra were taken every $5 \mathrm{~s}$. 
A)

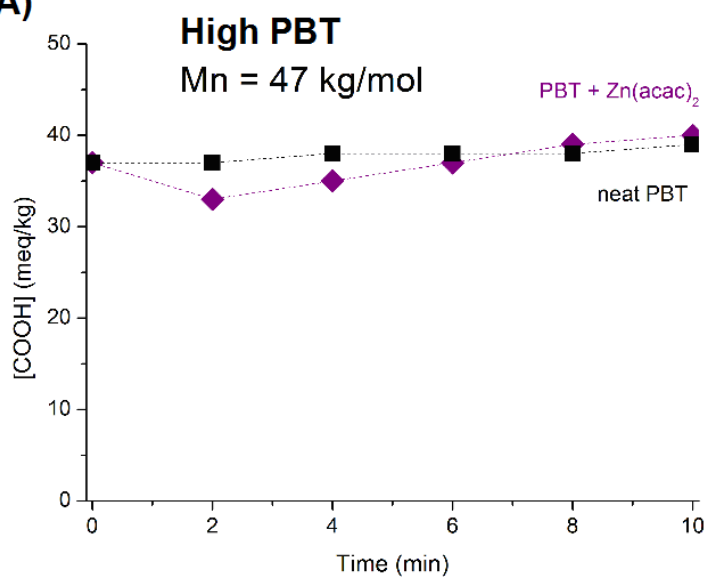

B)

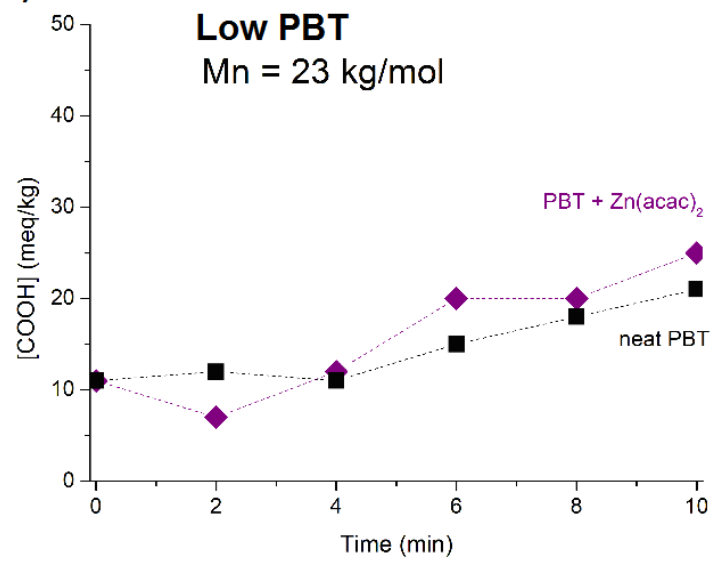

Figure S3 Variation of [COOH] end-group content as a function of extrusion time for PBT of two different molar masses with and without the presence of $\mathrm{Zn}(\mathrm{acac})_{2}$ at $[\mathrm{Zn}(\mathrm{II})] /([\mathrm{OH}]+[\mathrm{COOH}])$ molar ratio of $10 \%$.

A)

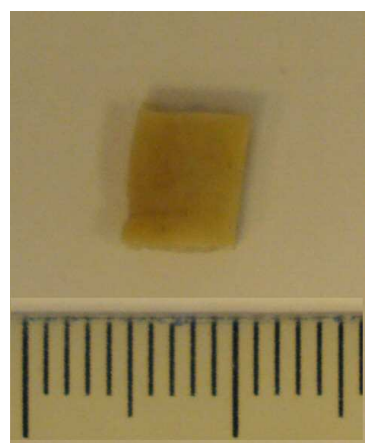

B)

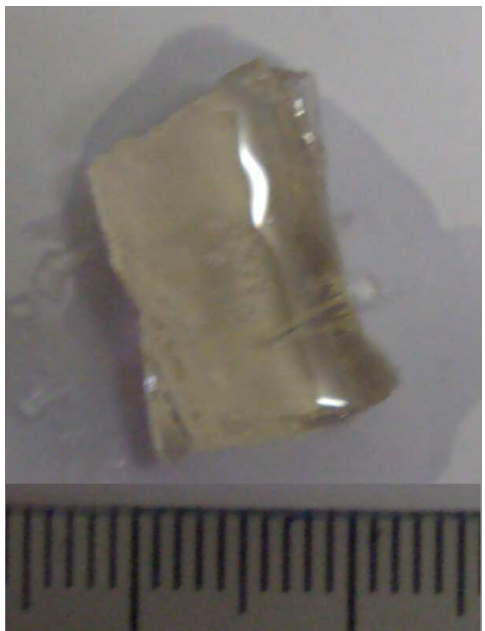

Figure S4 Visual aspect of an unswollen specimen of compound 4c (A) and the same after swelling in TCB (B). 

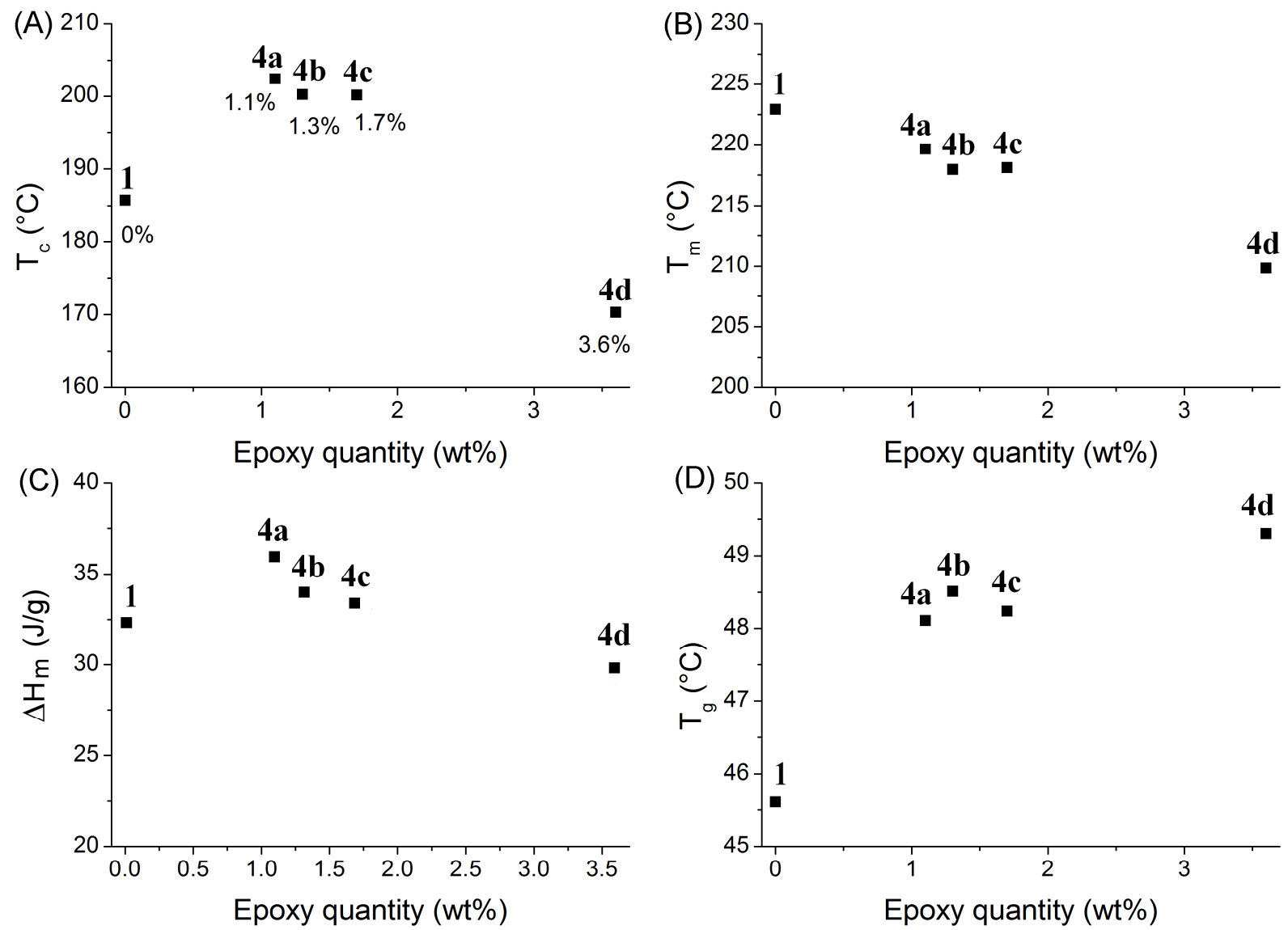

Figure S5 Effect of cross-linking through epoxy vitrimer chemistry on crystallization. Thermal analysis data of compounds 4a-4d as a function of the epoxy quantity: (A) crystallization temperature, (B) melting temperature, (C) melting enthalpy (integral between 75 and $232^{\circ} \mathrm{C}$ ) measured on 2nd heating, (corresponding degree of crystallinity, compound $1: \chi c=23.0 \%$, compound $4 \mathbf{a}: \chi c=25.6 \%$, compound $\mathbf{4 b}: \chi c=24.2 \%$, compound 4c: $\chi \mathrm{c}=23.7 \%$, compound $\mathbf{4 d}: \chi \mathrm{c}=21.1 \%$ ) and (D) glass transition temperature. 
Table S1 Characteristics of model compounds investigated.

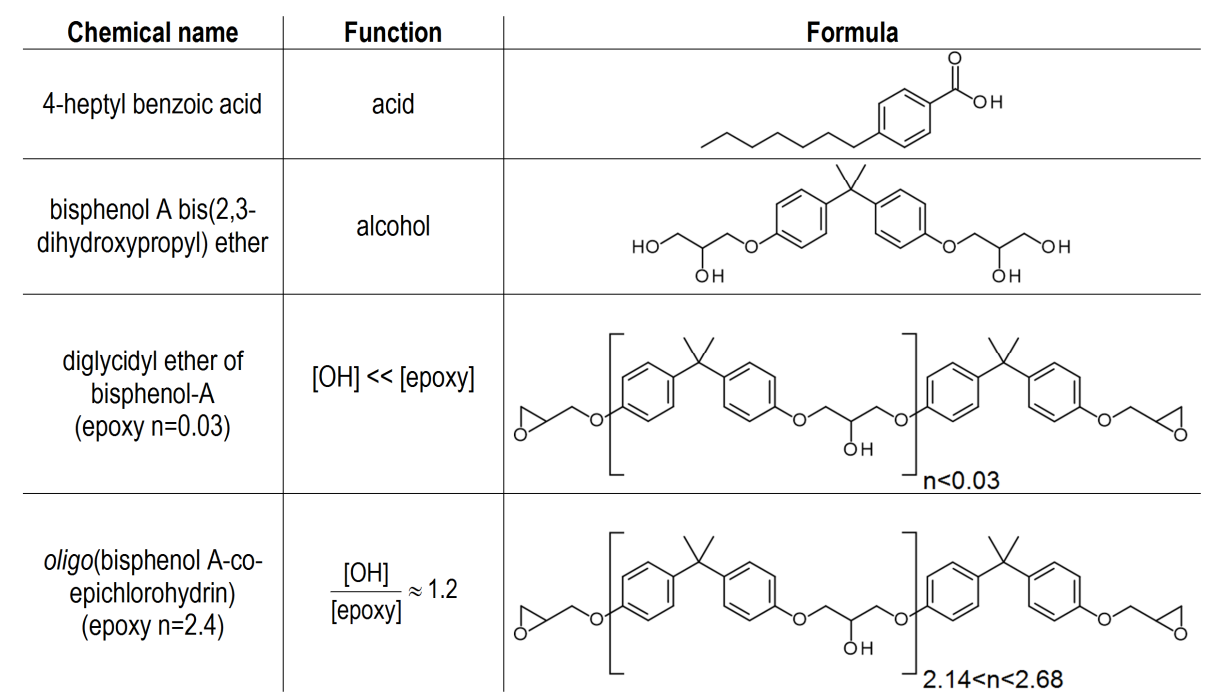

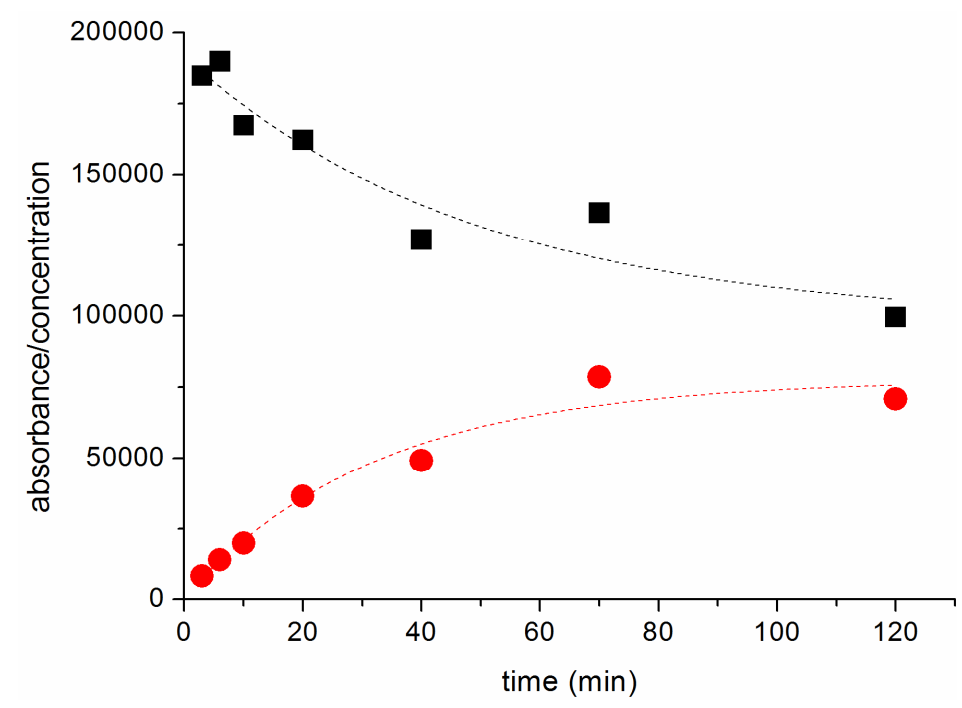

Figure S6 Kinetics of model molecules with 2-MI, The reaction is performed at $200^{\circ} \mathrm{C}$ in bulk between heptyl benzoic and phenyl glycidyl ether in the presence of $5 \mathrm{~mol} \%$ of 2-MI. Addition takes place within a few minutes, further evolution is analyzed by gas chromatography. The plot shows the time dependance of b-hydroxy-ester (mixture of isomers, black squares) and diester (red disks) concentrations. 